Supporting Information for:

\title{
The Total Synthesis of (+)-Dragmacidin F
}

\author{
Neil K. Garg, Daniel D. Caspi, Brian M. Stoltz*
}

The Arnold and Mabel Beckman Laboratories of Chemical Synthesis, Division of Chemistry and Chemical Engineering, California Institute of Technology, Pasadena, California 91125, USA

Materials and Methods. Unless stated otherwise, reactions were conducted in flame-dried glassware under an atmosphere of nitrogen using anhydrous solvents (either freshly distilled or passed through activated alumina columns). All commercially obtained reagents were used as received. Reaction temperatures were controlled using an IKAmag temperature modulator. Thinlayer chromatography (TLC) was conducted with E. Merck silica gel 60 F254 pre-coated plates, $(0.25 \mathrm{~mm})$ and visualized using a combination of UV, anisaldehyde, ceric ammonium molybdate, and potassium permanganate staining. ICN silica gel (particle size 0.032-0.063 mm) was used for flash column chromatography. Disposable Sep-Pak $\mathrm{C}_{18}$ Vac Cartridges were purchased from Waters and used for all reversed-phase filtrations. HPLC analysis was performed on a Beckman Gold system using a Rainin $\mathrm{C}_{18}$, Microsorb MV, $5 \mu \mathrm{m}, 300$ x $4.6 \mathrm{~mm}$ reversed-phased column in $0.1 \%(\mathrm{w} / \mathrm{v})$ TFA with acetonitrile as eluent and a flow rate of 1.0 $\mathrm{mL} / \mathrm{min}$, gradient elution of $1.25 \%$ acetonitrile/min. Preparatory reversed-phase HPLC was performed on a Beckman HPLC with a Waters DeltaPak 25 x $100 \mathrm{~mm}, 100 \mu \mathrm{m} \mathrm{C}_{18}$ column equipped with a guard, $0.1 \%(\mathrm{w} / \mathrm{v})$ TFA with acetonitrile as eluent, and gradient elution of $0.50 \%$ acetonitrile/min. For all reversed-phase purifications, water $(18 \mathrm{M} \Omega)$ was obtained from a Millipore MiliQ water purification system and TFA from Halocarbon, Inc. ${ }^{1} \mathrm{H}$ NMR spectra were recorded on a Varian Mercury 300 (at $300 \mathrm{MHz}$ ), a Varian Inova 500 (at $500 \mathrm{MHz}$ ), or a Varian Inova 600 (at $600 \mathrm{MHz}$ ) and are reported relative to $\mathrm{Me}_{4} \mathrm{Si}(\delta 0.0)$. Data for ${ }^{1} \mathrm{H}$ NMR spectra are reported as follows: chemical shift ( $\delta \mathrm{ppm})$, multiplicity, coupling constant $(\mathrm{Hz})$ and integration. ${ }^{13} \mathrm{C}$ NMR spectra were recorded on a Varian Mercury 300 (at $75 \mathrm{MHz}$ ), or a Varian Inova 500 (at $125 \mathrm{MHz}$ ) and are reported relative to $\mathrm{Me}_{4} \mathrm{Si}(\delta 0.0)$. Data for ${ }^{13} \mathrm{C}$ NMR spectra are reported 
in terms of chemical shift. IR spectra were recorded on a Perkin Elmer Paragon 1000 spectrometer and are reported in frequency of absorption $\left(\mathrm{cm}^{-1}\right)$. Optical rotations were measured with a Jasco P-1010 polarimeter. High resolution mass spectra were obtained from the California Institute of Technology Mass Spectral Facility. 


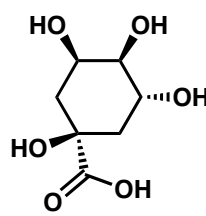

9
Amberlyst ${ }^{\circledR} 15 \mathrm{H}^{+}$resin

PhH, DMF, Dean-Stark, $\Delta$

(99\% yield)

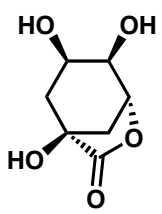

SM1

Lactone SM1. A mixture of D-(-)-quinic acid (9) (50.0 g, $260.2 \mathrm{mmol})$, Amberlyst ${ }^{\circledR} 15$ ion-exchange resin (7 g, $35 \mathrm{mmol})$, benzene $(500 \mathrm{~mL})$ and DMF (125 mL) was refluxed under a Dean-Stark trap for $16 \mathrm{~h}$. The reaction mixture was cooled to $23{ }^{\circ} \mathrm{C}$ and filtered over a pad of Celite. The filtrate was then evaporated under reduced pressure to afford a thick oil, which was diluted with $\mathrm{CH}_{2} \mathrm{Cl}_{2}(150 \mathrm{~mL})$. Hexanes $(250 \mathrm{~mL})$ was added and the resulting mixture was allowed to sit at $23{ }^{\circ} \mathrm{C}$ for $2 \mathrm{~h}$. The product was collected by vacuum filtration, and was further dried in vacuo to afford lactone SM1 (44.9 g, 99\% yield) as a white powder. $\mathrm{R}_{f} 0.40$ (3:1 EtOAc:acetone); characterization data for this compound have been previously reported. ${ }^{1}$
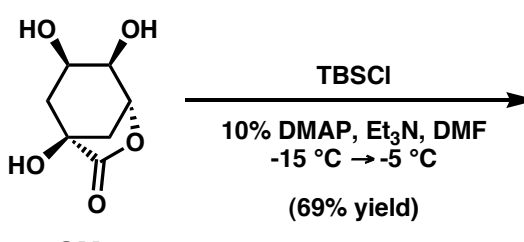

SM1

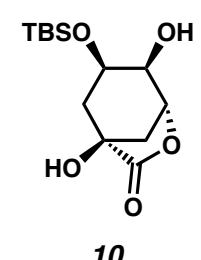

TBS Lactone 10. To a mixture of lactone SM1 (90.0 g, $517 \mathrm{mmol})$, DMAP (6.31 g, 51.7 $\mathrm{mmol})$, triethylamine $(90 \mathrm{~mL}, 646 \mathrm{mmol})$, and $\mathrm{DMF}(345 \mathrm{~mL})$ at $-15^{\circ} \mathrm{C}$ was added $\mathrm{TBSCl}(84.9$ $\mathrm{g}, 563 \mathrm{mmol}$ ) in 3 equal portions over $30 \mathrm{~min}$. The temperature was maintained between $-20{ }^{\circ} \mathrm{C}$ and $-15{ }^{\circ} \mathrm{C}$ during the addition. The reaction mixture was allowed to warm to $-5{ }^{\circ} \mathrm{C}$ over $3 \mathrm{~h}$, quenched by the addition of $5 \%$ aq. citric acid $(120 \mathrm{~mL})$, and then warmed to $23{ }^{\circ} \mathrm{C}$. The solvent was removed in vacuo, and the crude product was diluted with $5 \%$ aq. citric acid $(350 \mathrm{~mL})$ and extracted with $\mathrm{Et}_{2} \mathrm{O}(1 \times 500 \mathrm{~mL}, 2 \times 400 \mathrm{~mL})$. The combined organic layers were washed with $\mathrm{H}_{2} \mathrm{O}(2 \times 400 \mathrm{~mL})$ and brine $(400 \mathrm{~mL})$, dried over $\mathrm{MgSO}_{4}$, and evaporated under reduced pressure. The product was triturated with hexanes $(750 \mathrm{~mL})$ and collected by vacuum filtration. It was further dried under vacuum to afford TBS lactone $\mathbf{1 0}$ (102.8 g, 69\% yield) as a dry white

\footnotetext{
${ }^{1}$ Philippe, M.; Sepulchre, A. M.; Gero, S. D.; Loibner, H.; Streicher, W.; Stutz, P. J. Antibiot. 1982, 35, 1507-1512.
} 
solid. $\mathrm{R}_{f} 0.48$ (1:1 hexanes:EtOAc); $\mathrm{R}_{f} 0.28$ (2:1 $\mathrm{Et}_{2} \mathrm{O}$ :hexanes); characterization data for this compound have been previously reported. ${ }^{2}$

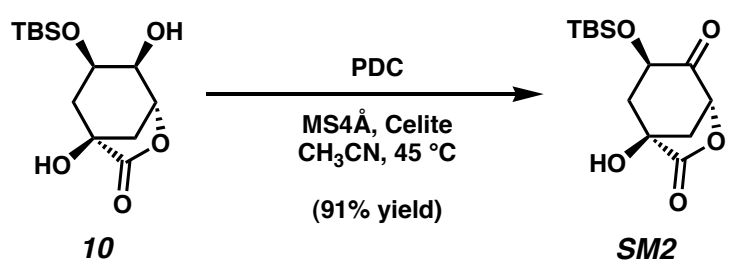

Keto Lactone SM2. A mixture of TBS lactone 10 (3.72 g, $12.90 \mathrm{mmol})$, powdered $4 \AA$ activated molecular sieves $(2.79 \mathrm{~g})$, Celite $(2.79 \mathrm{~g})$, pyridinium dichromate $(12.13 \mathrm{~g}, 32.2 \mathrm{mmol})$, and acetonitrile $(185 \mathrm{~mL})$ was heated to $45^{\circ} \mathrm{C}$ for $24 \mathrm{~h}$. The reaction was allowed to cool to 23 ${ }^{\circ} \mathrm{C}$, and then was filtered over a plug of silica gel topped with Celite (EtOAc eluent). The solvent was removed under reduced pressure to afford a brown oil, which was further purified by passage over a plug of silica gel (1:1 hexanes:EtOAc). Evaporating the solvent in vacuo afforded keto lactone SM2 (3.35 g, 91\% yield) as a pale yellow oil.

Alternate Procedure. Powdered $4 \AA$ activated molecular sieves $(184.6 \mathrm{~g})$ were agitated and flame-dried under vacuum for approximately 30 min until a fine, powder-like consistency was obtained. Upon cooling to $23{ }^{\circ} \mathrm{C}_{,} \mathrm{CH}_{2} \mathrm{Cl}_{2}(540 \mathrm{~mL})$ was introduced and the slurry was cooled to $0{ }^{\circ} \mathrm{C}$. Freshly prepared pyridinium dichromate ${ }^{3}(148.7 \mathrm{~g}, 395.3 \mathrm{mmol})$ was added, and the resulting heterogeneous orange mixture was treated with TBS lactone 10 (70.04 g, 242.8 mmol) portionwise over $4 \mathrm{~min}$. After the addition was complete, the reaction was stirred for 5 min and then freshly distilled $\mathrm{AcOH}(49.0 \mathrm{~mL}, 856.0 \mathrm{mmol})$ was added dropwise over a $20 \mathrm{~min}$ period. The reaction temperature was maintained at $0{ }^{\circ} \mathrm{C}$ for $15 \mathrm{~min}$ after the addition was complete, and was then stirred at $23{ }^{\circ} \mathrm{C}$. After $10 \mathrm{~h}$, the reaction was judged complete by ${ }^{1} \mathrm{H}$ NMR. The dark mixture was evenly divided into 3 portions, each of which was filtered over a pad of silica gel $(10 \mathrm{~cm}$ diameter x $7.5 \mathrm{~cm}$ height, EtOAc eluent). The filtrates were combined and evaporated in vacuo to afford a dark liquid, and this residue was further coevaporated with toluene $(3 \times 150 \mathrm{~mL})$. The crude product was diluted in a mixture of hexanes:EtOAc $(10: 1 ; 250$ $\mathrm{mL}$ ) and filtered over a pad of powdered $\mathrm{Na}_{2} \mathrm{SO}_{4}$ to remove insoluble impurities. The filtrate was evaporated, and dried in vacuo, to afford keto lactone SM2 (55.27 g, 80\% yield) as a brown,

\footnotetext{
${ }^{2}$ Manthey, M. K.; González-Bello, C.; Abell, C. J. Chem. Soc., Perkin Trans. 1, 1997, 5, 625-628.

${ }^{3}$ Xiao, W. Huaxue Shiji 1992, 14(6), 363-366.
} 
waxy solid. This material was used immediately in the next step without further purification. Unstable to TLC conditions; ${ }^{1} \mathrm{H}$ NMR $\left(300 \mathrm{MHz}, \mathrm{CDCl}_{3}\right): \delta 4.71(\mathrm{~d}, J=6.6 \mathrm{~Hz}, 1 \mathrm{H}), 4.52(\mathrm{dd}, J$ $=10.3 \mathrm{~Hz}, 8.9 \mathrm{~Hz}, 1 \mathrm{H}), 2.95(\mathrm{~s}, 1 \mathrm{H}), 2.88-2.79(\mathrm{~m}, 1 \mathrm{H}), 2.57-2.47(\mathrm{~m}, 1 \mathrm{H}), 2.39$ (d, J=12.4 Hz, $1 \mathrm{H}), 2.13(\mathrm{dd}, J=12.4 \mathrm{~Hz}, 10.5 \mathrm{~Hz}, 1 \mathrm{H}), 0.88(\mathrm{~s}, 9 \mathrm{H}), 0.11(\mathrm{~s}, 3 \mathrm{H}), 0.02(\mathrm{~s}, 3 \mathrm{H}) ;{ }^{13} \mathrm{C}$ NMR $(75$ $\mathrm{MHz}_{\mathrm{CDCl}}$ ): $\delta$ 202.6, 177.4, 79.0, 72.0, 70.6, 43.2, 42.6, 25.8 (3C), 18.5, -4.6, -5.3; IR (film): 3444 (br), 2931, 2858, 1799, 1753, 1254, 1144, $1111 \mathrm{~cm}^{-1}$; HRMS-FAB $(\mathrm{m} / z):[\mathrm{M}+\mathrm{H}]^{+}$calc'd for $\mathrm{C}_{13} \mathrm{H}_{23} \mathrm{O}_{5} \mathrm{Si}$, 287.1315; found, 287.1316; $[\alpha]^{19}{ }_{\mathrm{D}}-96.47^{\circ}\left(c 1.0, \mathrm{C}_{6} \mathrm{H}_{6}\right)$.

NOTE: Exposure of keto lactone SM2 to water (e.g. aqueous workup, or prolonged exposure to silica gel) led to the formation of hydrate $\mathbf{S M 3}$, as a white powder.

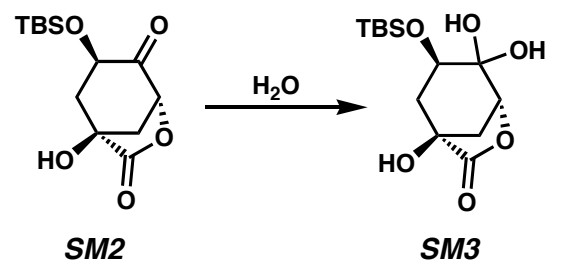

Unstable to TLC conditions; mp 104-6 ${ }^{\circ} \mathrm{C} ;{ }^{1} \mathrm{H}$ NMR (300 MHz, $\left.\mathrm{CD}_{3} \mathrm{OD}\right): \delta 4.46(\mathrm{~d}, J=5.8 \mathrm{~Hz}$, 1H), 3.75 (dd, $J=10.7 \mathrm{~Hz}, 7.0 \mathrm{~Hz}, 1 \mathrm{H}), 2.48-2.31$ (comp. m, 2H), 2.10-2.00 (m, 1H), 1.76 (app. t, $J=11.4 \mathrm{~Hz}, 1 \mathrm{H}), 0.93(\mathrm{~s}, 9 \mathrm{H}), 0.14(\mathrm{~s}, 3 \mathrm{H}), 0.12(\mathrm{~s}, 3 \mathrm{H}) ;{ }^{13} \mathrm{C}$ NMR $\left(75 \mathrm{MHz}, \mathrm{CD}_{3} \mathrm{OD}\right): \delta$ 179.4, 93.2, 81.8, 73.0, 72.3, 41.5, 40.9, 26.5 (3C), 19.1, -4.3, -4.7; IR (KBr): 3440 (br), 3374 (br), 2929, 2858, 1782, 1256, 1108, $1070 \mathrm{~cm}^{-1}$; HRMS-CI $(\mathrm{m} / \mathrm{z}):[\mathrm{M}+\mathrm{H}]^{+}$calc'd for $\mathrm{C}_{13} \mathrm{H}_{24} \mathrm{O}_{6} \mathrm{Si}$, 304.1342; found, 304.1336; $[\alpha]^{19}{ }_{\mathrm{D}}-54.29^{\circ}(c 1.0, \mathrm{MeOH})$.

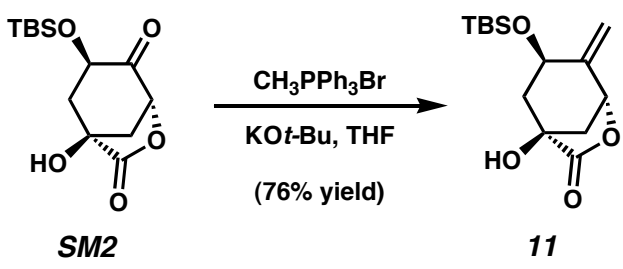

Methylene Lactone 11. To $\mathrm{CH}_{3} \mathrm{PPh}_{3} \mathrm{Br}(105 \mathrm{mg}, 0.293 \mathrm{mmol})$ in $\mathrm{THF}(2.8 \mathrm{~mL})$ at $0{ }^{\circ} \mathrm{C}$ was added potassium $t$-butoxide $(31.3 \mathrm{mg}, 0.279 \mathrm{mmol})$. The mixture was warmed to $23{ }^{\circ} \mathrm{C}$ and stirred for an additional $10 \mathrm{~min}$. Keto lactone SM2 (40 mg, $0.140 \mathrm{mmol})$ in THF (1 mL) was added and stirring was continued at $23{ }^{\circ} \mathrm{C}$ for $15 \mathrm{~min}$. The reaction mixture was then refluxed for $2 \mathrm{~h}$ and cooled to $23^{\circ} \mathrm{C}$. The solvent was removed under reduced pressure and the residue was partitioned between $\mathrm{Et}_{2} \mathrm{O}(3 \mathrm{~mL})$ and brine $(1.5 \mathrm{~mL})$. The layers were separated and the aqueous 
layer was further extracted with $\mathrm{Et}_{2} \mathrm{O}(3 \times 1 \mathrm{~mL})$. The combined organic layers were washed with brine $(1.5 \mathrm{~mL})$, dried by passage over a plug of silica gel $\left(\mathrm{Et}_{2} \mathrm{O}\right.$ eluent, then 2:1 hexanes:EtOAc eluent), and evaporated under reduced pressure. The crude product was purified by flash chromatography (2:1 hexanes:EtOAc) to afford methylene lactone 11 (30 mg, 76\% yield) as a white solid.

Alternate Procedure. To $\mathrm{CH}_{3} \mathrm{PPh}_{3} \mathrm{Br}(82.9 \mathrm{~g}, 232.1 \mathrm{mmol})$ in THF $(1.10 \mathrm{~L})$ at $23{ }^{\circ} \mathrm{C}$ was added potassium $t$-butoxide $(23.8 \mathrm{~g}, 212.1 \mathrm{mmol})$ in one portion. The mixture was stirred for $2 \mathrm{~h}$, then cooled to $0{ }^{\circ} \mathrm{C}$. Keto lactone SM2 $(54.5 \mathrm{~g}, 190.3 \mathrm{mmol})$ in THF $(240 \mathrm{~mL})$ was added dropwise over a $30 \mathrm{~min}$ period. The reaction was allowed to warm slowly to $23{ }^{\circ} \mathrm{C}$ over $9 \mathrm{~h}$, then quenched by the addition of ice-cold $15 \%$ aq. $\mathrm{NH}_{4} \mathrm{Cl}(500 \mathrm{~mL})$. The solvent was evaporated under reduced pressure, and the residue was partitioned between $\mathrm{Et}_{2} \mathrm{O}(500 \mathrm{~mL})$ and $\mathrm{H}_{2} \mathrm{O}(100$ $\mathrm{mL})$. The aqueous phase was extracted with $\mathrm{Et}_{2} \mathrm{O}(3 \times 250 \mathrm{~mL})$ and the combined organics were washed with $\mathrm{H}_{2} \mathrm{O}(100 \mathrm{~mL})$ and brine $(100 \mathrm{~mL})$, and dried over $\mathrm{MgSO}_{4}$. Evaporation of the solvent afforded a crude yellow oil, which was filtered over a plug of silica gel (4:1 pentane: $\mathrm{Et}_{2} \mathrm{O}$ $\rightarrow$ 3:2 pentane:Et $t_{2} \mathrm{O}$ eluent). After evaporating the solvent in vacuo, the residue was triturated with ice-cold pentane $(40 \mathrm{~mL})$. The white solid was filtered, and washed with ice-cold pentane (2 x $2 \mathrm{~mL}$ ). A second crop was collected from the filtrate after concentrating its volume to $15 \mathrm{~mL}$. Drying the collected material in vacuo afforded methylene lactone $11(22.1 \mathrm{~g}, 41 \%$ yield) as a white solid. $\mathrm{R}_{f} 0.59$ (1:1 hexanes:EtOAc); $\mathrm{mp} 87-88{ }^{\circ} \mathrm{C} ;{ }^{1} \mathrm{H}$ NMR $\left(300 \mathrm{MHz}, \mathrm{CDCl}_{3}\right)$ : $\delta 5.25-$ $5.23(\mathrm{~m}, 1 \mathrm{H}), 5.13-5.10(\mathrm{~m}, 1 \mathrm{H}), 5.07(\mathrm{~d}, J=6.0 \mathrm{~Hz}, 1 \mathrm{H}), 4.38-4.29(\mathrm{~m}, 1 \mathrm{H}), 2.85$ (s, 1H), 2.672.59 (m, 1H), 2.31-2.21 (m, 1H), 2.09 (d, $J=11.5 \mathrm{~Hz}, 1 \mathrm{H}), 1.86$ (app. t, $J=11.3 \mathrm{~Hz}, 1 \mathrm{H}), 0.89$ (s, 9H), $0.06(\mathrm{~s}, 6 \mathrm{H}) ;{ }^{13} \mathrm{C} \mathrm{NMR}\left(75 \mathrm{MHz}, \mathrm{CDCl}_{3}\right): \delta$ 178.1, 144.8, 111.0, 79.4, 73.1, 67.1, 44.7, 44.7, 26.0 (3C), 18.5, -4.5, -4.7; IR (film): 3426 (br), 2956, 2931, 2858, 1791, 1254, 1120, 1071 $\mathrm{cm}^{-1}$; HRMS-FAB $(\mathrm{m} / \mathrm{z}):[\mathrm{M}+\mathrm{H}]^{+}$calc'd for $\mathrm{C}_{14} \mathrm{H}_{25} \mathrm{O}_{4} \mathrm{Si}$, 285.1522; found, 285.1519; $[\alpha]^{19}{ }_{\mathrm{D}}$ $101.71^{\circ}\left(c 1.0, \mathrm{CHCl}_{3}\right)$. 


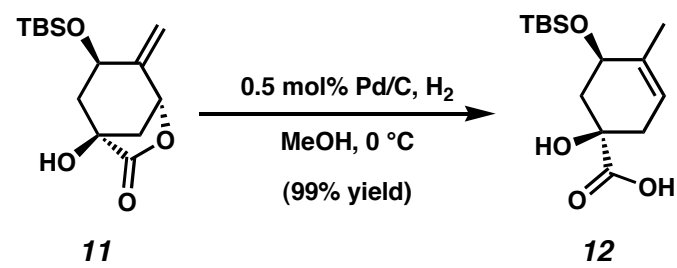

Acid 12. A mixture of methylene lactone 11 (4.0 g, $14.1 \mathrm{mmol})$ and 10\% $\mathrm{Pd} / \mathrm{C}(80 \mathrm{mg}$, $0.075 \mathrm{mmol})$ in methanol $(120 \mathrm{~mL})$ was cooled to $0{ }^{\circ} \mathrm{C}$. The reaction vessel was evacuated and back-filled with $\mathrm{H}_{2}(3 \mathrm{x})$. After $7 \mathrm{~h}$ at $0{ }^{\circ} \mathrm{C}$, the mixture was filtered over a pad of Celite $(\mathrm{MeOH}$ eluent) and the solvent was evaporated under reduced pressure to afford a colorless oil. Residual solvent was removed by holding the crude product under vacuum for $10 \mathrm{~h}$, providing acid 12 (4.0 g, 99\% yield), which was used immediately without further purification. $\mathrm{R}_{f} 0.28$ (1:1 hexanes:EtOAc; $1 \%$ acetic acid); ${ }^{1} \mathrm{H}$ NMR $\left(300 \mathrm{MHz}, \mathrm{CDCl}_{3}\right): \delta 5.88(\mathrm{~s}, 1 \mathrm{H}), 5.53-5.48(\mathrm{~m}, 1 \mathrm{H})$, 4.16-4.11 (m, 1H), 2.71-2.60 (m, 1H), 2.36-2.22 (m, 1H), $2.18(\mathrm{dd}, J=14.3 \mathrm{~Hz}, 3.9 \mathrm{~Hz}, 1 \mathrm{H})$, 2.08-2.01 (m, 1H), 1.79-1.76 (m, 3H), 0.89 (s, 9H), 0.15-0.13 (comp. m, 6H); ${ }^{13} \mathrm{C}$ NMR (75 $\left.\mathrm{MHz}_{\mathrm{CDCl}}\right): \delta 176.4,133.2,121.1,73.6,68.6,37.9,35.9,25.8$ (3C), 21.4, 18.0, -4.5, -4.7; IR (film): 3356 (br), 2956, 2931, 2858, 1768 (br), 1718 (br), 1255, $1063 \mathrm{~cm}^{-1}$; HRMS-FAB (m/z): $[\mathrm{M}+\mathrm{H}]^{+}$calc'd for $\mathrm{C}_{14} \mathrm{H}_{27} \mathrm{O}_{4} \mathrm{Si}$, 287.1679; found, 287.1675; $[\alpha]^{19}{ }_{\mathrm{D}}+37.58^{\circ}\left(c 1.0, \mathrm{C}_{6} \mathrm{H}_{6}\right)$.

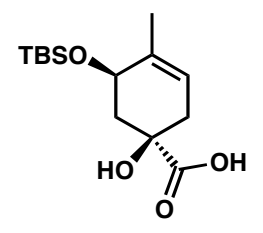

12

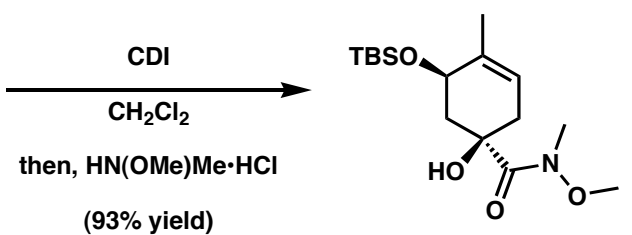

13

Weinreb Amide 13. To acid $12(4.0 \mathrm{~g}, 14.1 \mathrm{mmol})$ in $\mathrm{CH}_{2} \mathrm{Cl}_{2}(70 \mathrm{~mL})$ at $23{ }^{\circ} \mathrm{C}$ was added 1,1'-carbonyldiimidazole $(3.65 \mathrm{~g}, 22.5 \mathrm{mmol})$ in equal portions over $15 \mathrm{~min}$. After the final addition, stirring was continued for $10 \mathrm{~min}$, then $\mathrm{N}, \mathrm{O}$-dimethylhydroxylamine $\bullet \mathrm{HCl}(3.43$ $\mathrm{g}, 35.16 \mathrm{mmol}$ ) was added in one portion. The reaction was allowed to stir at $23{ }^{\circ} \mathrm{C}$ for $3 \mathrm{~h}$. $\mathrm{Et}_{2} \mathrm{O}$ was added $(50 \mathrm{~mL})$ and the reaction mixture was filtered. The filtrate was evaporated, diluted with $\mathrm{Et}_{2} \mathrm{O}(125 \mathrm{~mL})$, washed with $5 \%$ aq. citric acid $(2 \times 50 \mathrm{~mL})$ and brine $(50 \mathrm{~mL})$, and dried over $\mathrm{MgSO}_{4}$. The crude product was purified by flash chromatography (3:1 hexanes:EtOAc) to afford Weinreb amide 13 (4.29 g, 93\% yield) as a colorless oil. $\mathrm{R}_{f} 0.42$ (2:1 hexanes:EtOAc); ${ }^{1} \mathrm{H}$ NMR (300 MHz, $\left.\mathrm{CDCl}_{3}\right): \delta 5.43(\mathrm{~m}, 1 \mathrm{H}), 4.72(\mathrm{~s}, 1 \mathrm{H}), 4.17-4.11(\mathrm{~m}, 1 \mathrm{H}), 3.71(\mathrm{~s}, 3 \mathrm{H}), 3.22(\mathrm{~s}$, 
3H), 2.59-2.24 (comp. m, 3H), 2.03 (dd, $J=14.6 \mathrm{~Hz}, 4.1 \mathrm{~Hz}, 1 \mathrm{H}), 1.75-1.71$ (m, 3H), 0.86 (s, 9H), 0.11 (s, 3H), 0.09 (s, 3H); $\left.{ }^{13} \mathrm{C} \mathrm{NMR} \mathrm{(75} \mathrm{MHz,} \mathrm{CDCl}_{3}, 15 / 16 \mathrm{C}\right): \delta$ 133.5, 121.5, 74.3, 69.4, 61.2, 38.1, 35.9, 26.0, 25.9 (3C), 21.3, 18.1, -4.3, -4.7; IR (film): 3463 (br), 2956, 2932, 2858, 1655, 1362, $1254 \mathrm{~cm}^{-1}$; HRMS-EI $(\mathrm{m} / \mathrm{z})$ : $[\mathrm{M}+\mathrm{H}]^{+}$calc'd for $\mathrm{C}_{16} \mathrm{H}_{32} \mathrm{NO}_{4} \mathrm{Si}, 330.2101$; found, $330.2085 ;[\alpha]^{19}{ }_{\mathrm{D}}+41.13^{\circ}\left(c 1.0, \mathrm{CHCl}_{3}\right)$.

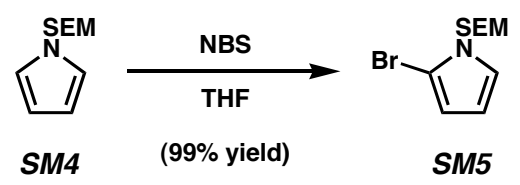

Bromopyrrole SM5. To SEM pyrrole SM4 $4^{4}(1.25 \mathrm{~g}, 6.33 \mathrm{mmol})$ in THF $(125 \mathrm{~mL})$ at 23 ${ }^{\circ} \mathrm{C}$ was added freshly recrystallized NBS $(1.127 \mathrm{~g}, 6.33 \mathrm{mmol})$ in one portion. After stirring for 5 min, additional NBS was added (15 mg, $0.084 \mathrm{mmol})$ and the reaction was immediately judged complete by TLC. The reaction mixture was poured into saturated aq. $\mathrm{NaHCO}_{3}(100 \mathrm{~mL})$ and extracted with $\mathrm{Et}_{2} \mathrm{O}(1 \times 100 \mathrm{~mL}, 2 \times 50 \mathrm{~mL})$. The combined organic layers were washed with brine $(75 \mathrm{~mL})$, dried over $\mathrm{MgSO}_{4}$, and evaporated under reduced pressure. The crude product was purified by passage over a plug of silica gel $\left(\mathrm{CH}_{2} \mathrm{Cl}_{2}\right.$ eluent) to afford bromopyrrole SM5 (1.73 g, 99\% yield) as a pale yellow oil. $\mathrm{R}_{f} 0.53$ (1:1 $\mathrm{CH}_{2} \mathrm{Cl}_{2}$ :hexanes); ${ }^{1} \mathrm{H}$ NMR (300 MHz, $\mathrm{CDCl}_{3}$ ): $\delta 6.83$ (app. t, $J=2.5 \mathrm{~Hz}, 1 \mathrm{H}$ ), 6.18-6.16 (comp. m, 2H), 5.22 (s, 2H), 3.53-3.46 (m, 2H), 0.92-0.85 (m, 2H), -0.03 (s, 9H); ${ }^{13} \mathrm{C}$ NMR (75 MHz, $\left.\mathrm{CDCl}_{3}\right)$ : $\delta$ 122.9, 111.9, 110.1, 102.0, 76.7, 66.0, 17.9, -1.2 (3C); IR (film): 2953, 2895, 1264, 1249, 1108, $1085 \mathrm{~cm}^{-1}$; HRMS-EI (m/z): $[\mathrm{M}+\mathrm{H}]^{+}$calc'd for $\mathrm{C}_{10} \mathrm{H}_{18} \mathrm{NOSiBr}, 275.0341$; found, 275.0331 .
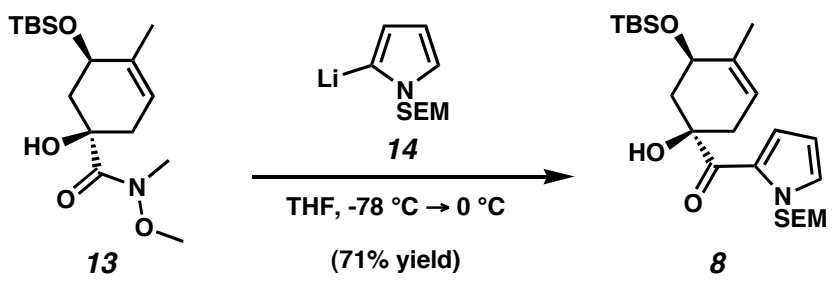

Acyl Pyrrole 8. To bromopyrrole SM5 $(1.73 \mathrm{~g}, 6.26 \mathrm{mmol})$ in THF $(42 \mathrm{~mL})$ at $-78{ }^{\circ} \mathrm{C}$ was added $n$-BuLi (2.25 M in hexanes, $2.7 \mathrm{~mL}, 6.16 \mathrm{mmol})$ dropwise over $1 \mathrm{~min}$. After $10 \mathrm{~min}$ at $-78^{\circ} \mathrm{C}$, Weinreb amide 13 (655 $\left.\mathrm{mg}, 1.99 \mathrm{mmol}\right)$ in THF $(5 \mathrm{~mL})$ was added dropwise over $1 \mathrm{~min}$.

\footnotetext{
${ }^{4}$ Muchowski, J. M.; Solas, D. R. J. Org. Chem. 1984, 49, 203-205.
} 
The reaction vessel was immediately warmed to $0{ }^{\circ} \mathrm{C}$, stirred for $25 \mathrm{~min}$, and cooled to $-78{ }^{\circ} \mathrm{C}$. The reaction mixture was quenched with saturated aq. $\mathrm{NH}_{4} \mathrm{Cl}(10 \mathrm{~mL})$, then warmed to $23{ }^{\circ} \mathrm{C}$. The volatiles were removed under reduced pressure. The residue was partitioned between $\mathrm{Et}_{2} \mathrm{O}$ (75 mL) and $\mathrm{H}_{2} \mathrm{O}(50 \mathrm{~mL})$ and the layers were separated. The aqueous layer was further extracted with $\mathrm{Et}_{2} \mathrm{O}(2 \times 40 \mathrm{~mL})$. The combined organic layers were washed with brine $(50 \mathrm{~mL})$, dried over $\mathrm{MgSO}_{4}$, and evaporated under reduced pressure. The crude product was purified by flash chromatography (23:1 hexanes:EtOAc, then 15:1 hexanes:EtOAc) to afford acyl pyrrole 8 (656 mg, 71\% yield) as a colorless oil. $\mathrm{R}_{f} 0.30$ (9:1 hexanes:EtOAc); ${ }^{1} \mathrm{H}$ NMR (300 MHz, $\left.\mathrm{CDCl}_{3}\right): \delta 7.66(\mathrm{dd}, J=4.0 \mathrm{~Hz}, 1.7 \mathrm{~Hz}, 1 \mathrm{H}), 7.06(\mathrm{dd}, J=2.5 \mathrm{~Hz}, 1.7 \mathrm{~Hz}, 1 \mathrm{H}), 6.19$ (dd, $J=4.0$ $\mathrm{Hz}, 2.5 \mathrm{~Hz}, 1 \mathrm{H}), 5.71$ (d, $J=10.4 \mathrm{~Hz}, 1 \mathrm{H}), 5.67$ (d, $J=10.0 \mathrm{~Hz}, 1 \mathrm{H}), 5.52-5.47$ (m, 1H), 4.90 (s, 1H), 4.19 (app. t, $J=3.1 \mathrm{~Hz}, 1 \mathrm{H}$ ), 3.51 (t, $J=8.3 \mathrm{~Hz}, 2 \mathrm{H}$ ), 2.52-2.46 (comp. m, 2H), 2.19-2.16 (comp. m, 2H), 1.80-1.78 (m, 3H), 0.92-0.88 (comp. m, 11H), 0.13 (s, 6H), -0.06 (s, 9H); ${ }^{13} \mathrm{C}$ NMR (75 MHz, $\left.\mathrm{CDCl}_{3}, 22 / 24 \mathrm{C}\right): \delta$ 193.7, 133.5, 129.9, 128.0, 123.8, 121.7, 109.0, 78.2, 69.4, 66.3, 38.6, 38.3, 26.0 (3C), 21.5, 18.1, -1.2 (3C), -4.2, -4.7; IR (film): 3476, 2954, 2931, 2859, 1639, 1412, 1310, 1251, $1085 \mathrm{~cm}^{-1}$; HRMS-EI $(\mathrm{m} / \mathrm{z}):[\mathrm{M}+\mathrm{H}]^{+}$calc'd for $\mathrm{C}_{24} \mathrm{H}_{44} \mathrm{NO}_{4} \mathrm{Si}_{2}$, 466.2809; found, 466.2822; $[\alpha]^{19}{ }_{\mathrm{D}}+34.25^{\circ}\left(c 1.0, \mathrm{C}_{6} \mathrm{H}_{6}\right)$.

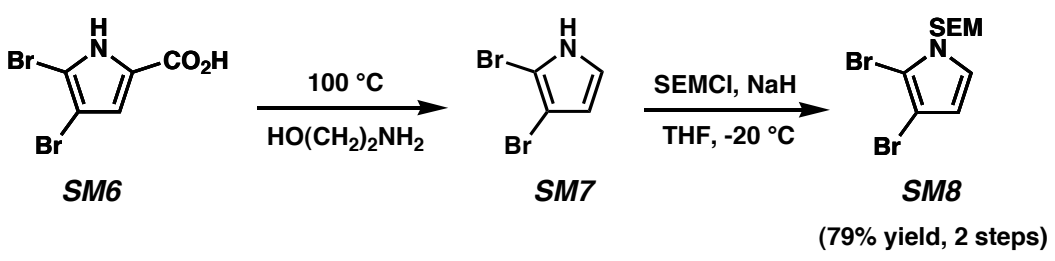

Dibromopyrrole SM8. A solution of 4,5-dibromopyrrole carboxylic acid (SM6) $)^{5}(6.05$ g, $22.5 \mathrm{mmol})$ in ethanolamine $(36 \mathrm{~mL})$ was heated to $100{ }^{\circ} \mathrm{C}$ for $2 \mathrm{~h}$, cooled to $23{ }^{\circ} \mathrm{C}$, and poured into a mixture of $\mathrm{Et}_{2} \mathrm{O}(200 \mathrm{~mL})$ and $0.5 \mathrm{~N}$ aq. $\mathrm{HCl}(300 \mathrm{~mL})$. The layers were separated, and the aqueous layer was extracted with $\mathrm{Et}_{2} \mathrm{O}(2 \times 250 \mathrm{~mL})$. The combined organic layers were washed with brine $(200 \mathrm{~mL})$, dried over $\mathrm{MgSO}_{4}$, and concentrated to $100 \mathrm{~mL}$. The solution was diluted with hexanes $(100 \mathrm{~mL})$, filtered over a plug of silica gel $\left(2: 1\right.$ hexanes: $\left.\mathrm{Et}_{2} \mathrm{O}\right)$, and concentrated to $150 \mathrm{~mL}$. THF $(100 \mathrm{~mL})$ was added, and the solution was concentrated to 100 $\mathrm{mL}$. This solvent exchange procedure was repeated 2 additional times $(2 \times 100 \mathrm{~mL}$ THF $)$ to

\footnotetext{
${ }^{5}$ Bailey, D. M.; Johnson, R. E. J. Med. Chem. 1973, 16, 1300-1302.
} 
afford 2,3-dibromopyrrole (SM7) as a solution in THF which was used immediately in the subsequent reaction.

CAUTION: Concentrating the above described solutions to dryness or near-dryness leads to rapid decomposition of 2,3-dibromopyrrole (SM7). ${ }^{6}$

To 2,3 dibromopyrrole (SM7) in THF at $-20{ }^{\circ} \mathrm{C}$ was added $\mathrm{NaH}(60 \%$ dispersion in mineral oil, $1.51 \mathrm{~g}, 37.8 \mathrm{mmol}$ ) in 3 equal portions over $3 \mathrm{~min}$. After $10 \mathrm{~min}$ at $-20{ }^{\circ} \mathrm{C}, \mathrm{SEMCl}$ $(4.8 \mathrm{~mL}, 27.1 \mathrm{mmol})$ was added dropwise over $1 \mathrm{~min}$. The reaction mixture was allowed to warm to $-8{ }^{\circ} \mathrm{C}$ over 40 min and was then quenched with saturated aq. $\mathrm{NH}_{4} \mathrm{Cl}(30 \mathrm{~mL})$. After warming to $23{ }^{\circ} \mathrm{C}$, the reaction mixture was diluted with $\mathrm{Et}_{2} \mathrm{O}(75 \mathrm{~mL})$ and $\mathrm{H}_{2} \mathrm{O}(20 \mathrm{~mL})$ and the layers were separated. The aqueous layer was further extracted with $\mathrm{Et}_{2} \mathrm{O}(2 \times 50 \mathrm{~mL})$. The combined organic layers were washed with brine $(50 \mathrm{~mL})$, dried over $\mathrm{MgSO}_{4}$, and evaporated under reduced pressure. The crude product was purified by flash chromatography $\left(6: 1\right.$ hexanes: $\mathrm{CH}_{2} \mathrm{Cl}_{2}$, then 4:1 hexanes: $\left.\mathrm{CH}_{2} \mathrm{Cl}_{2}\right)$ to afford dibromopyrrole $\mathbf{S M 8}\left(6.25 \mathrm{~g}, 79 \%\right.$ yield) as a yellow oil. $\mathrm{R}_{f}$ $0.17\left(6: 1\right.$ hexanes: $\left.\mathrm{CH}_{2} \mathrm{Cl}_{2}\right) ;{ }^{1} \mathrm{H} \mathrm{NMR}\left(300 \mathrm{MHz}, \mathrm{CDCl}_{3}\right): \delta 6.82(\mathrm{~d}, J=3.6 \mathrm{~Hz}, 1 \mathrm{H}), 6.25(\mathrm{~d}, J=$ $3.3 \mathrm{~Hz}, 1 \mathrm{H}), 5.21(\mathrm{~s}, 2 \mathrm{H}), 3.48(\mathrm{t}, J=8.1 \mathrm{~Hz}, 2 \mathrm{H}), 0.88(\mathrm{t}, J=8.1 \mathrm{~Hz}, 2 \mathrm{H}),-0.03(\mathrm{~s}, 9 \mathrm{H}) ;{ }^{13} \mathrm{C}$ NMR (75 MHz, $\mathrm{CDCl}_{3}$ ): $\delta 123.1,112.3,103.7,99.8,77.8,66.2,17.9$, -1.2 (3C); IR (film): 2953, 2896, 1514, 1470, 1279, 1250, 1109, $1084 \mathrm{~cm}^{-1}$; HRMS-EI $(\mathrm{m} / z):[\mathrm{M}+\mathrm{H}]^{+}$calc'd for $\mathrm{C}_{10} \mathrm{H}_{17} \mathrm{NOSiBr}_{2}, 352.9446$; found, 352.9435 .
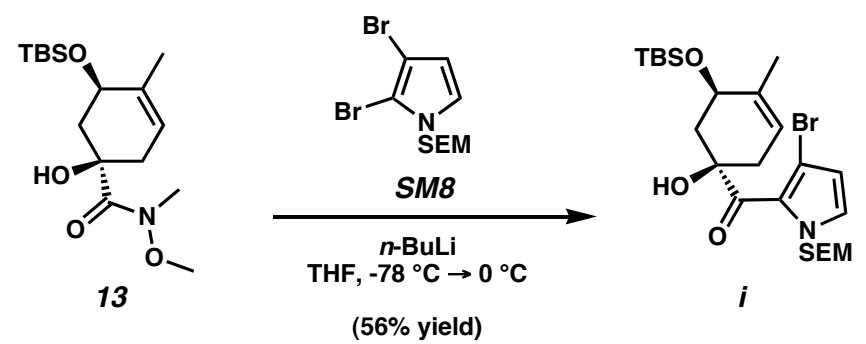

Bromo Acyl Pyrrole i. To dibromopyrrole SM8 (6.02 g, $17.06 \mathrm{mmol})$ in THF (114 mL) at $-78{ }^{\circ} \mathrm{C}$ was added $n$-BuLi $(2.5 \mathrm{M}$ in hexanes, $6.7 \mathrm{~mL}, 16.8 \mathrm{mmol})$ dropwise over $1 \mathrm{~min}$. After $10 \mathrm{~min}$ at $-78{ }^{\circ} \mathrm{C}$, Weinreb amide 13 (1.58 g, $\left.4.80 \mathrm{mmol}\right)$ in THF (15 mL) was added dropwise over 30 seconds. The reaction vessel was immediately warmed to $0{ }^{\circ} \mathrm{C}$, stirred for $90 \mathrm{~min}$, and cooled to $-78{ }^{\circ} \mathrm{C}$. The reaction was quenched with saturated aq. $\mathrm{NH}_{4} \mathrm{Cl}(15 \mathrm{~mL})$, then warmed to $23{ }^{\circ} \mathrm{C}$. The volatiles were removed in vacuo, and the residue was partitioned between $\mathrm{Et}_{2} \mathrm{O}(75$

\footnotetext{
${ }^{6}$ Audebert, P.; Bidan, G. Synthetic Metals 1986, 15, 9-22.
} 
$\mathrm{mL})$ and $\mathrm{H}_{2} \mathrm{O}(30 \mathrm{~mL})$. The layers were separated, and the aqueous layer was further extracted with $\mathrm{Et}_{2} \mathrm{O}(2 \times 50 \mathrm{~mL})$. The combined organic layers were washed with brine $(50 \mathrm{~mL})$, dried over $\mathrm{MgSO}_{4}$, and evaporated under reduced pressure. The crude product was purified by flash chromatography (11:9 $\mathrm{CH}_{2} \mathrm{Cl}_{2}$ :hexanes) to afford bromo acyl pyrrole $\mathbf{i}$ (1.47 g, 56\% yield) as a colorless oil. $\mathrm{R}_{f} 0.29$ (11:9 hexanes: $\left.\mathrm{CH}_{2} \mathrm{Cl}_{2}\right) ;{ }^{1} \mathrm{H} \mathrm{NMR}\left(300 \mathrm{MHz}, \mathrm{CDCl}_{3}\right): \delta 6.77(\mathrm{~d}, J=2.9 \mathrm{~Hz}$, $1 \mathrm{H}), 6.20(\mathrm{~d}, \mathrm{~J}=2.7 \mathrm{~Hz}, 1 \mathrm{H}), 5.53-5.47(\mathrm{~m}, 1 \mathrm{H}), 5.35(\mathrm{~d}, J=10.4 \mathrm{~Hz}, 1 \mathrm{H}), 5.29$ (d, $J=10.4 \mathrm{~Hz}$, $1 \mathrm{H}), 4.72(\mathrm{~s}, 1 \mathrm{H}), 4.18-4.14(\mathrm{~m}, 1 \mathrm{H}), 3.31(\mathrm{t}, J=8.2 \mathrm{~Hz}, 2 \mathrm{H}), 2.65-2.53(\mathrm{~m}, 1 \mathrm{H}), 2.53-2.41(\mathrm{~m}$, 1H), 2.32 (dt, $J=14.3 \mathrm{~Hz}, 1.7 \mathrm{~Hz}, 1 \mathrm{H}), 2.15$ (dd, $J=14.2 \mathrm{~Hz}, 4 \mathrm{~Hz}, 1 \mathrm{H}), 1.79-1.76$ (m, 3H), $0.87(\mathrm{~s}, 9 \mathrm{H}), 0.81(\mathrm{t}, J=8.2 \mathrm{~Hz}, 2 \mathrm{H}), 0.12(\mathrm{~s}, 6 \mathrm{H}),-0.06(\mathrm{~s}, 9 \mathrm{H}) ;{ }^{13} \mathrm{C} \mathrm{NMR}\left(75 \mathrm{MHz}, \mathrm{CDCl}_{3}\right): \delta$ 201.9, 133.2, 129.6, 125.0, 121.6, 112.5, 101.8, 78.9, 78.6, 68.9, 66.2, 38.6, 37.4, 26.0 (3C), 21.5, 18.1, 17.8, -1.2 (3C), -4.1, -4.7; IR (film): 3477 (br), 2953, 1664 (br), 1400, 1253, $1101 \mathrm{~cm}^{-}$

1; HRMS-EI $(m / z):[\mathrm{M}+\mathrm{H}]^{+}$calc'd for $\mathrm{C}_{24} \mathrm{H}_{43} \mathrm{NO}_{4} \mathrm{Si}_{2} \mathrm{Br}$, 544.1914; found, 544.1903; $[\alpha]^{19}{ }_{\mathrm{D}}$ $+1.64^{\circ}\left(c 1.0, \mathrm{CHCl}_{3}\right)$.
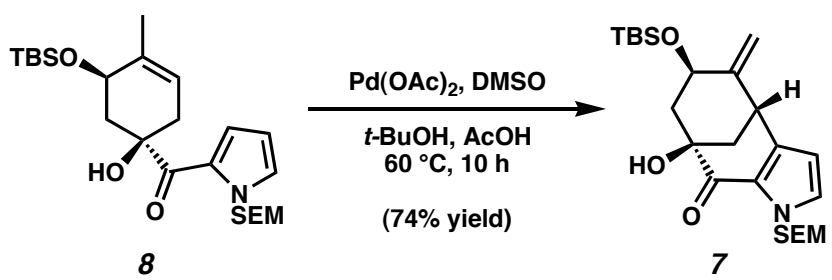

[3.3.1] Bicycle 7. To acyl pyrrole $8(106.0 \mathrm{mg}, 0.227 \mathrm{mmol})$ was added $\mathrm{Pd}(\mathrm{OAc})_{2}(51.1$ $\mathrm{mg}, 0.227 \mathrm{mmol}), \mathrm{DMSO}(32.3 \mu \mathrm{L}, 0.455 \mathrm{mmol}), t$-BuOH $(18.2 \mathrm{~mL})$, and AcOH $(4.5 \mathrm{~mL})$. The mixture was heated to $60{ }^{\circ} \mathrm{C}$ for $10 \mathrm{~h}$, cooled to $23{ }^{\circ} \mathrm{C}$, and filtered over a plug of silica gel $(3: 1$ hexanes:EtOAc). The solvent was evaporated, and the residue was again filtered over a plug of silica gel (3:1 hexanes:EtOAc). After removal of solvent in vacuo, the product was purified by flash chromatography on silica gel (6:1 hexanes:EtOAc) to afford [3.3.1] bicycle 7 (78.4 mg, $74 \%$ yield) as a pale yellow oil. $\mathrm{R}_{f} 0.20$ (4:1 hexanes:EtOAc); ${ }^{1} \mathrm{H}$ NMR $\left(300 \mathrm{MHz}, \mathrm{CDCl}_{3}\right): \delta$ $7.07(\mathrm{~d}, J=2.7 \mathrm{~Hz}, 1 \mathrm{H}), 6.05(\mathrm{~d}, J=2.7 \mathrm{~Hz}, 1 \mathrm{H}), 5.71(\mathrm{~d}, J=9.9 \mathrm{~Hz}, 1 \mathrm{H}), 5.58(\mathrm{~d}, J=9.9 \mathrm{~Hz}$, 1H), 5.09-5.05 (m, 2H), $4.00(\mathrm{~s}, 1 \mathrm{H}), 3.99-3.90(\mathrm{~m}, 1 \mathrm{H}), 3.84$ (app. t, $J=3.0 \mathrm{~Hz}, 1 \mathrm{H}), 3.55-3.47$ (m, 2H), 2.39 (app. dt, $J=7.4 \mathrm{~Hz}, 3.8 \mathrm{~Hz}, 1 \mathrm{H}$ ), 2.13-2.03 (comp. m, 2H), 1.73 (app. t, $J=11.8$ $\mathrm{Hz}, 1 \mathrm{H}), 0.98-0.76$ (comp. m, 11H), -0.04 (s, 9H), -0.11 (s, 6H); ${ }^{1} \mathrm{H}$ NMR $\left(300 \mathrm{MHz}, \mathrm{C}_{6} \mathrm{D}_{6}\right): \delta$ $6.53(\mathrm{~d}, J=2.5 \mathrm{~Hz}, 1 \mathrm{H}), 5.77(\mathrm{~d}, J=2.8 \mathrm{~Hz}, 1 \mathrm{H}), 5.55$ (d, $J=10.2 \mathrm{~Hz}, 1 \mathrm{H}), 5.32$ (app. t, $J=1.9$ 
Hz, 1H), 5.26 (d, $J=10.2 \mathrm{~Hz}, 1 \mathrm{H}), 5.01-4.97(\mathrm{~m}, 1 \mathrm{H}), 4.29(\mathrm{~s}, 1 \mathrm{H}), 4.27-4.19(\mathrm{~m}, 1 \mathrm{H}), 3.59-3.47$ (comp. m, 3H), 2.45-2.31 (comp. m, 2H), 2.16 (dd, $J=12.1 \mathrm{~Hz}, 3.0 \mathrm{~Hz}, 1 \mathrm{H}$ ), 2.07 (app. t, $J=$ $11.8 \mathrm{~Hz}, 1 \mathrm{H}), 0.92-0.89$ (comp. m, 11H), 0.01 (s, 9H), -0.06 (s, 3H), -0.07 (s, 3H); ${ }^{13} \mathrm{C}$ NMR (75 $\left.\mathrm{MHz}, \mathrm{C}_{6} \mathrm{D}_{6}\right): \delta 191.5,149.4,141.8,132.0,125.5,108.5,107.4,76.8,75.8,68.4,66.3,48.9,45.5$, 40.7, 26.3 (3C), 18.8, 18.2, -0.8 (3C), -4.4, -4.7; IR (film): 3480, 2953, 2858, 1651, 1420, 1318, 1251, 1100, $1077 \mathrm{~cm}^{-1}$; HRMS-FAB $(\mathrm{m} / \mathrm{z})$ : $[\mathrm{M}]^{+}$calc'd for $\mathrm{C}_{24} \mathrm{H}_{41} \mathrm{NO}_{4} \mathrm{Si}_{2}, 463.2574$; found, $463.2577 ;[\alpha]^{23}{ }_{\mathrm{D}}-275.07^{\circ}\left(c 1.0, \mathrm{CHCl}_{3}\right)$.
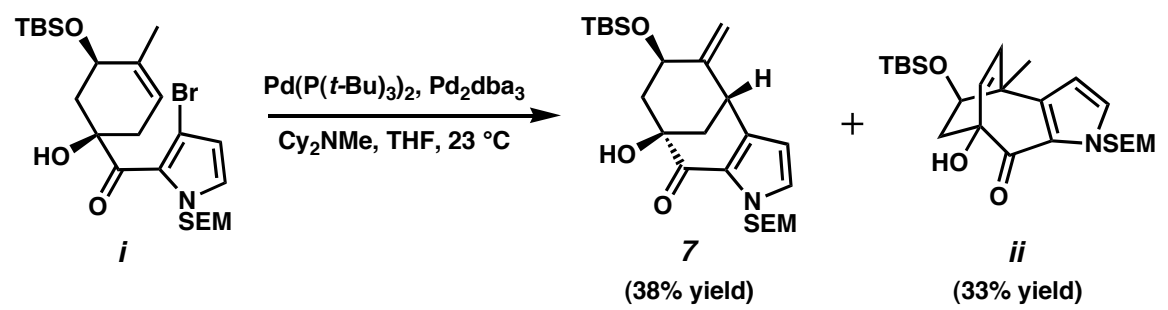

Alternate Procedure. Bromo acyl pyrrole i (52.0 mg, $0.0955 \mathrm{mmol}), \mathrm{Pd}_{2} \mathrm{dba}_{3}(21.9 \mathrm{mg}$, $0.0239 \mathrm{mmol}), \mathrm{Pd}\left(\mathrm{P}(t-\mathrm{Bu})_{3}\right)_{2}(24.4 \mathrm{mg}, 0.0477 \mathrm{mmol})$, THF $(1.2 \mathrm{~mL})$, and $\mathrm{Cy}_{2} \mathrm{NMe}(24.3 \mu \mathrm{L}$, $0.115 \mathrm{mmol}$ ) were combined under a glovebox atmosphere and stirred at $23{ }^{\circ} \mathrm{C}$ for $10 \mathrm{~h}$. The reaction vessel was removed from the glovebox, diluted with 3:1 hexanes:EtOAc (2 mL), and filtered over a plug of silica gel topped with Celite (3:1 hexanes:EtOAc eluent). The solvent was removed under reduced pressure and the residue was purified by flash chromatography $\left(\mathrm{CH}_{2} \mathrm{Cl}_{2}\right.$, then $3: 1$ hexanes:EtOAc). The crude product was further purified by flash chromatography $(6: 1$ hexanes:EtOAc) to afford [3.3.1] bicycle 7 (16.7 $\mathrm{mg}, 38 \%$ yield) and [3.2.2] bicycle ii (14.4 mg, $33 \%$ yield), both as pale yellow oils.

[3.2.2] Bicycle ii: $\mathrm{R}_{f} 0.42$ (5:1 hexanes:EtOAc); ${ }^{1} \mathrm{H}$ NMR $\left(300 \mathrm{MHz}, \mathrm{CDCl}_{3}\right): \delta 6.98(\mathrm{~d}, J=2.7$ $\mathrm{Hz}, 1 \mathrm{H}), 6.15(\mathrm{~d}, J=2.7 \mathrm{~Hz}, 1 \mathrm{H}), 6.02(\mathrm{~d}, J=9.3 \mathrm{~Hz}, 1 \mathrm{H}), 5.98(\mathrm{~d}, J=8.8 \mathrm{~Hz}, 1 \mathrm{H}), 5.69(\mathrm{~d}, J=$ $9.9 \mathrm{~Hz}, 1 \mathrm{H}), 5.62(\mathrm{~d}, J=9.9 \mathrm{~Hz}, 1 \mathrm{H}), 4.93(\mathrm{~s}, 1 \mathrm{H}), 3.81$ (d, $J=7.7 \mathrm{~Hz}, 1 \mathrm{H}), 3.50$ (t, $J=8.0 \mathrm{~Hz}$, 2H), 2.36 (dd, $J=14.3 \mathrm{~Hz}, 7.7 \mathrm{~Hz}, 1 \mathrm{H}), 1.94$ (dd, $J=14.3 \mathrm{~Hz}, 1.6 \mathrm{~Hz}, 1 \mathrm{H}), 1.55$ (s, 3H), 0.910.83 (comp. m, 11H), 0.02 (s, 3H), 0.01 (s, 3H), -0.07 (s, 9H); ${ }^{1} \mathrm{H}$ NMR (300 MHz, $\left.\mathrm{C}_{6} \mathrm{D}_{6}\right): \delta 6.55$ $(\mathrm{d}, J=2.7 \mathrm{~Hz}, 1 \mathrm{H}), 6.23(\mathrm{~d}, J=8.8 \mathrm{~Hz}, 1 \mathrm{H}), 5.96(\mathrm{~d}, J=3.3 \mathrm{~Hz}, 1 \mathrm{H}), 5.94(\mathrm{~d}, J=9.2 \mathrm{~Hz}, 1 \mathrm{H})$, $5.59(\mathrm{~d}, J=10.4 \mathrm{~Hz}, 1 \mathrm{H}), 5.40(\mathrm{~d}, J=9.9 \mathrm{~Hz}, 1 \mathrm{H}), 5.32(\mathrm{~s}, 1 \mathrm{H}), 3.82-3.75(\mathrm{~m}, 1 \mathrm{H}), 3.46(\mathrm{t}, J=$ $7.7 \mathrm{~Hz}, 2 \mathrm{H}), 2.46(\mathrm{dd}, J=13.7 \mathrm{~Hz}, 7.7 \mathrm{~Hz}, 1 \mathrm{H}), 2.25$ (dd, $J=13.7 \mathrm{~Hz}, 1.6 \mathrm{~Hz}, 1 \mathrm{H}), 1.52(\mathrm{~s}, 3 \mathrm{H})$, 
$0.92(\mathrm{~s}, 9 \mathrm{H}), 0.82(\mathrm{t}, J=8.0 \mathrm{~Hz}, 2 \mathrm{H}),-0.03(\mathrm{~s}, 3 \mathrm{H}),-0.08(\mathrm{~s}, 3 \mathrm{H}),-0.09(\mathrm{~s}, 9 \mathrm{H}) ;{ }^{13} \mathrm{C}$ NMR $(75$ $\left.\mathrm{MHz}_{\mathrm{CDCl}}\right): \delta 188.7,144.1,139.4,134.5,129.1,121.8,107.7,78.2,77.8,73.3,66.4,45.7$, 45.0, 26.0 (3C), 22.2, 18.2, 18.0, -1.25 (3C), -4.1, -4.6; IR (film): 3432, 2955, 2858, 1645, 1250, $1081 \mathrm{~cm}^{-1}$; HRMS-EI $(\mathrm{m} / \mathrm{z}):[\mathrm{M}+\mathrm{H}]^{+}$calc'd for $\mathrm{C}_{24} \mathrm{H}_{42} \mathrm{NO}_{4} \mathrm{Si}_{2}, 464.2652$; found, 464.2665; $[\alpha]^{19}{ }_{\mathrm{D}}+19.22^{\circ}\left(c 1.0, \mathrm{C}_{6} \mathrm{H}_{6}\right)$.

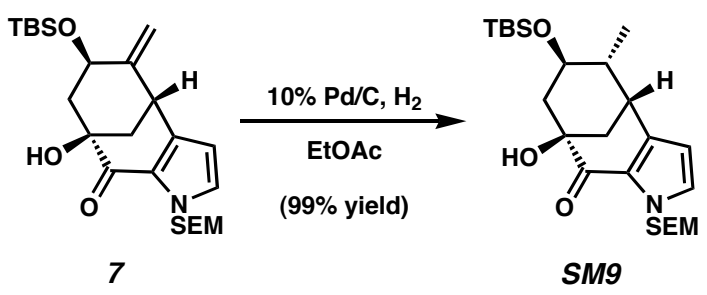

Reduced [3.3.1] Bicycle SM9. [3.3.1] bicycle 7 (360 mg, $0.78 \mathrm{mmol}), 10 \% \mathrm{Pd} / \mathrm{C}$ (130 $\mathrm{mg}, 0.12 \mathrm{mmol})$, and EtOAc $(8 \mathrm{~mL})$ were combined, and the reaction vessel was evacuated and back-filled with $\mathrm{H}_{2}(1 \mathrm{~atm})$. The reaction mixture was stirred under $\mathrm{H}_{2}$ for $30 \mathrm{~min}$, then filtered over a plug of silica gel topped with Celite (EtOAc eluent) to afford reduced [3.3.1] bicycle SM9 as a colorless oil (358 mg, 99\% yield). $\mathrm{R}_{f} 0.28$ (5:1 hexanes:EtOAc); ${ }^{1} \mathrm{H}$ NMR (300 MHz, $\left.\mathrm{C}_{6} \mathrm{D}_{6}\right)$ : $\delta 6.55(\mathrm{~d}, J=2.5 \mathrm{~Hz}, 1 \mathrm{H}), 5.74(\mathrm{~d}, J=2.5 \mathrm{~Hz}, 1 \mathrm{H}), 5.56(\mathrm{~d}, J=10.2 \mathrm{~Hz}, 1 \mathrm{H}), 5.30(\mathrm{~d}, J=10.2$ $\mathrm{Hz}, 1 \mathrm{H}), 4.27$ (s, 1H), 3.59-3.45 (m, 2H), 3.19 (ddd, $J=12.9 \mathrm{~Hz}, 7.7 \mathrm{~Hz}, 3.3 \mathrm{~Hz}, 1 \mathrm{H}), 2.58$ (dd, $J$ $=6.5 \mathrm{~Hz}, 3.2 \mathrm{~Hz}, 1 \mathrm{H}$ ), 2.37-2.20 (comp. m, 2H), 2.06-1.90 (comp. m, 2H), 1.63-1.50 (m, 1H), $1.00(\mathrm{~d}, J=6.6 \mathrm{~Hz}, 3 \mathrm{H}), 0.94-0.89$ (comp. m, 11H), -0.02 (s, 9H), -0.06 (s, 3H), -0.09 (s, 3H); ${ }^{13} \mathrm{C}$ NMR $\left(75 \mathrm{MHz}, \mathrm{CDCl}_{3}\right): \delta 190.8,140.4,131.3,125.2,110.1,76.6,75.6,71.8,66.1,46.8$, 44.3, 40.0, 37.3, 25.9 (3C), 18.1, 17.9, 16.5, -1.2 (3C), -4.0, -4.6; IR (film): 3473 (br), 2953, 2931, 2857, 1651, 1420, 1249, $1079 \mathrm{~cm}^{-1}$; HRMS-EI $(\mathrm{m} / \mathrm{z})$ : $[\mathrm{M}+\mathrm{H}]^{+}$calc'd for $\mathrm{C}_{24} \mathrm{H}_{44} \mathrm{NO}_{4} \mathrm{Si}_{2}$, 466.2809; found, 466.2804; $[\alpha]^{19}{ }_{\mathrm{D}}-166.30^{\circ}\left(c\right.$ 1.0, $\left.\mathrm{C}_{6} \mathrm{H}_{6}\right)$.

NOTE: In some instances, trace phosphine contaminants from the Heck reaction (i.e. $\boldsymbol{i} \rightarrow 7$ ) prevented the reduction from occurring. Simply working up the reaction and re-exposing it to the identical reaction conditions (as described above) allowed the reduction to proceed. 

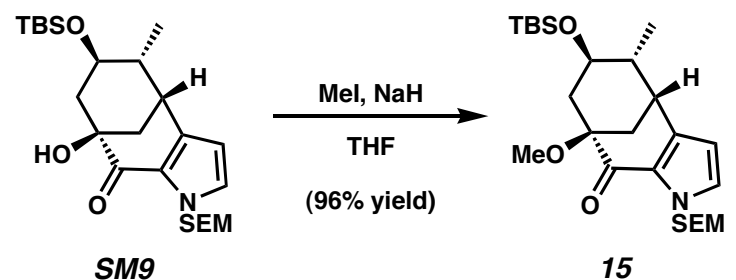

Methyl Ether 15. To reduced [3.3.1] bicycle SM9 (358 mg, $0.77 \mathrm{mmol})$ in THF (7.7 $\mathrm{mL})$ at $23{ }^{\circ} \mathrm{C}$ was added $\mathrm{NaH}(60 \%$ dispersion in mineral oil, $123 \mathrm{mg}, 3.08 \mathrm{mmol})$. After stirring for $2 \mathrm{~min}$ at $23{ }^{\circ} \mathrm{C}$, MeI was added $(335 \mu \mathrm{L}, 5.38 \mathrm{mmol})$. The resulting mixture was stirred for 1 h, cooled to $0{ }^{\circ} \mathrm{C}$, and quenched with saturated aq. $\mathrm{NH}_{4} \mathrm{Cl}(4 \mathrm{~mL})$, then warmed to $23{ }^{\circ} \mathrm{C} \mathrm{Et}_{2} \mathrm{O}$ $(10 \mathrm{~mL})$ and $\mathrm{H}_{2} \mathrm{O}(5 \mathrm{~mL})$ were added, and the layers were separated. The aqueous layer was further extracted with $\mathrm{Et}_{2} \mathrm{O}(2 \times 15 \mathrm{~mL})$. The combined organic layers were washed with brine $(20 \mathrm{~mL})$, dried over $\mathrm{MgSO}_{4}$, and evaporated under reduced pressure. The crude product was purified by flash chromatography (4:1 hexanes:EtOAc) to afford methyl ether 15 (354 mg, 96\% yield) as a colorless oil. $\mathrm{R}_{f} 0.34$ (5:1 hexanes:EtOAc); ${ }^{1} \mathrm{H}$ NMR $\left(300 \mathrm{MHz}, \mathrm{C}_{6} \mathrm{D}_{6}\right): \delta 6.58(\mathrm{~d}, J=$ $2.8 \mathrm{~Hz}, 1 \mathrm{H}), 5.78$ (d, $J=2.5 \mathrm{~Hz}, 1 \mathrm{H}), 5.57$ (d, $J=10.2 \mathrm{~Hz}, 1 \mathrm{H}), 5.54$ (d, $J=10.2 \mathrm{~Hz}, 1 \mathrm{H}), 3.65-$ 3.50 (m, 2H), 3.37 (s, 3H), 3.22 (ddd, $J=12.9 \mathrm{~Hz}, 7.9 \mathrm{~Hz}, 3.1 \mathrm{~Hz}, 1 \mathrm{H}), 2.68$ (dd, $J=6.5 \mathrm{~Hz}, 3.2$ Hz, 1H), 2.59-2.49 (comp. m, 2H), 1.86 (dd, $J=12.4$ Hz, $11.3 \mathrm{~Hz}, 1 \mathrm{H}$ ), 1.72-1.56 (m, 2H), 1.04 (d, $J=6.9 \mathrm{~Hz}, 3 \mathrm{H}), 0.93-0.85$ (comp. m, $11 \mathrm{H}),-0.02$ (s, 9H), -0.07 (s, 3H), -0.10 (s, 3H); ${ }^{13} \mathrm{C}$ NMR (75 MHz, $\left.\mathrm{C}_{6} \mathrm{D}_{6}, 24 / 25 \mathrm{C}\right): \delta 189.4,138.3,130.4,109.7,81.9,76.9,72.4,66.2,51.8,45.9$, 41.3, 41.2, 37.6, 26.4 (3C), 18.5, 18.3, 17.0, -0.9 (3C), -3.6, -4.4; IR (film): 2954, 1657, 1421, 1250, $1085 \mathrm{~cm}^{-1}$; HRMS-EI $(\mathrm{m} / \mathrm{z}):[\mathrm{M}+\mathrm{H}]^{+}$calc'd for $\mathrm{C}_{25} \mathrm{H}_{46} \mathrm{NO}_{4} \mathrm{Si}_{2}, 480.2965$; found, $480.2970 ;[\alpha]^{19}-172.9^{\circ}\left(c 1.0, \mathrm{C}_{6} \mathrm{H}_{6}\right)$.

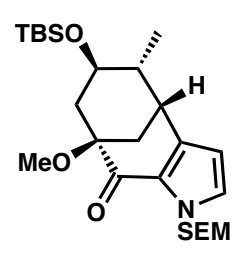

15

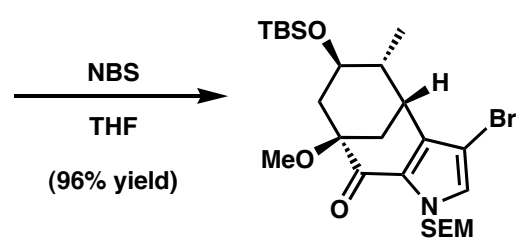

SM10

Bromide SM10. To methyl ether 15 (305 $\mathrm{mg}, 0.64 \mathrm{mmol})$ in THF $(6 \mathrm{~mL})$ at $0{ }^{\circ} \mathrm{C}$ was added freshly recrystallized NBS $(147 \mathrm{mg}, 0.83 \mathrm{mmol})$. After stirring for $10 \mathrm{~min}$ at $0{ }^{\circ} \mathrm{C}$, the reaction mixture was warmed to $23{ }^{\circ} \mathrm{C}$ and additional NBS (30 mg, $0.17 \mathrm{mmol}$ ) was added. After $5 \mathrm{~min}$, the reaction was quenched with saturated aq. $\mathrm{Na}_{2} \mathrm{~S}_{2} \mathrm{O}_{3}$, diluted with $\mathrm{H}_{2} \mathrm{O}(15 \mathrm{~mL})$ 
and extracted with $\mathrm{Et}_{2} \mathrm{O}(3 \times 15 \mathrm{~mL})$. The combined organic layers were washed with brine (15 $\mathrm{mL}$ ), dried over $\mathrm{MgSO}_{4}$, and evaporated under reduced pressure. The crude product was purified by flash chromatography (5:1 hexanes:EtOAc) to afford bromide SM10 (340 $\mathrm{mg}, 96 \%$ yield) as a colorless oil. $\mathrm{R}_{f} 0.55$ (3:1 hexanes:EtOAc); ${ }^{1} \mathrm{H}$ NMR $\left(300 \mathrm{MHz}, \mathrm{C}_{6} \mathrm{D}_{6}\right): \delta 6.57(\mathrm{~s}, 1 \mathrm{H}), 5.46(\mathrm{~d}$, $J=10.2 \mathrm{~Hz}, 1 \mathrm{H}), 5.34(\mathrm{~d}, J=10.2 \mathrm{~Hz}, 1 \mathrm{H}), 3.57-3.41(\mathrm{~m}, 2 \mathrm{H}), 3.32-3.20(\mathrm{~m}, 4 \mathrm{H}), 2.88(\mathrm{dd}, J=$ $6.5 \mathrm{~Hz}, 3.2 \mathrm{~Hz}, 1 \mathrm{H}), 2.46$ (ddd, $J=12.2 \mathrm{~Hz}, 5.1 \mathrm{~Hz}, 2.5 \mathrm{~Hz}, 1 \mathrm{H}), 2.28$ (app. dt, $J=7.4 \mathrm{~Hz}, 4.0$ $\mathrm{Hz}, 1 \mathrm{H}), 1.78$ (app. t, $J=11.8 \mathrm{~Hz}, 1 \mathrm{H}), 1.69-1.57$ (m, 1H), 1.52 (dd, $J=11.8 \mathrm{~Hz}, 3.0 \mathrm{~Hz}, 1 \mathrm{H})$, 1.19 (d, $J=6.9 \mathrm{~Hz}, 3 \mathrm{H}), 0.91-0.80$ (comp. m, 11H), -0.05 (s, 9H), -0.09 (s, 3H), -0.12 (s, 3H); ${ }^{13} \mathrm{C}$ NMR $\left(75 \mathrm{MHz}, \mathrm{C}_{6} \mathrm{D}_{6}\right): \delta 189.6,147.2,137.2,130.1,98.4,81.8,77.0,72.1,66.6,51.8,45.8$, 42.4, 41.0, 35.9, 26.3 (3C), 18.5, 18.3, 17.8, -0.9 (3C), -3.7, -4.3; IR (film): 2954, 2930, 1664, 1249, $1089 \mathrm{~cm}^{-1}$; HRMS-EI $(\mathrm{m} / \mathrm{z}):[\mathrm{M}+\mathrm{H}]^{+}-\mathrm{H}_{2}$ calc'd for $\mathrm{C}_{25} \mathrm{H}_{43} \mathrm{NO}_{4} \mathrm{Si}_{2} \mathrm{Br}$, 556.1914; found, $556.1928 ;[\alpha]^{19}-98.22^{\circ}\left(c 1.0, \mathrm{C}_{6} \mathrm{H}_{6}\right)$.

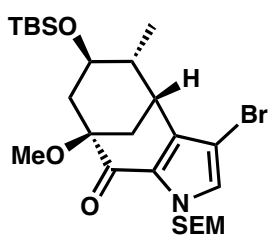

SM10

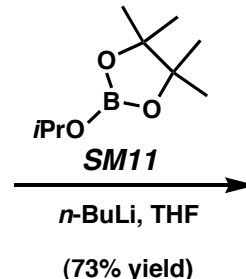

(73\% yield)

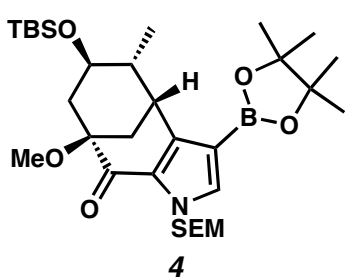

Boronic Ester 4. To bromide SM10 (116 mg, $0.21 \mathrm{mmol}$ ) and 2-isopropoxy-4,4,5,5tetramethyl-1,3,2-dioxaborolane (SM11) $(847 \mu \mathrm{L}, 4.15 \mathrm{mmol})$ in THF $(10.4 \mathrm{~mL})$ at $-78{ }^{\circ} \mathrm{C}$ was added $n \operatorname{BuLi}(2.3 \mathrm{M}$ in hexanes, $1.35 \mathrm{~mL}, 3.11 \mathrm{mmol})$ dropwise over $2 \mathrm{~min}$. After stirring for 15 min at $-78{ }^{\circ} \mathrm{C}$, the reaction mixture was quenched with saturated aq. $\mathrm{NH}_{4} \mathrm{Cl}$, warmed to $23{ }^{\circ} \mathrm{C}$, and diluted with $\mathrm{H}_{2} \mathrm{O}(10 \mathrm{~mL})$. The mixture was extracted with $\mathrm{Et}_{2} \mathrm{O}(3 \times 15 \mathrm{~mL})$. The combined organic layers were washed with brine $(15 \mathrm{~mL})$, dried over $\mathrm{MgSO}_{4}$, and evaporated under reduced pressure. The crude product was purified by flash chromatography (4:1 hexanes:EtOAc with $\left.0.5 \% \mathrm{Et}_{3} \mathrm{~N}\right)$ to afford boronic ester $4(92 \mathrm{mg}, 73 \%$ yield) as a white powder which was used immediately in the next step. $\mathrm{R}_{f} 0.50$ (3:1 hexanes:EtOAc); mp 143-145 ${ }^{\circ} \mathrm{C} ;{ }^{1} \mathrm{H}$ NMR $(300 \mathrm{MHz}$, $\left.\mathrm{C}_{6} \mathrm{D}_{6}\right): \delta 7.42(\mathrm{~s}, 1 \mathrm{H}), 5.55(\mathrm{~d}, J=10.1 \mathrm{~Hz}, 1 \mathrm{H}), 5.51(\mathrm{~d}, J=9.8 \mathrm{~Hz}, 1 \mathrm{H}), 3.74-3.68(\mathrm{~m}, 1 \mathrm{H})$, 3.60-3.50 (m, 2H), 3.43-3.36 (m, 1H), 3.33 (s, 3H), 2.65-2.53 (comp. m, 2H), 1.91 (app. t, $J=$ $11.8 \mathrm{~Hz}, 1 \mathrm{H}), 1.89-1.80(\mathrm{~m}, 1 \mathrm{H}), 1.68$ (dd, $J=11.8 \mathrm{~Hz}, 2.8 \mathrm{~Hz}, 1 \mathrm{H}), 1.34$ (d, $J=6.6 \mathrm{~Hz}, 3 \mathrm{H})$, $1.15(\mathrm{~s}, 6 \mathrm{H}), 1.14(\mathrm{~s}, 6 \mathrm{H}), 0.94-0.81$ (comp. m, 11H), -0.04 (s, 3H), -0.05 (s, 9H), -0.07 (s, 3H); 
${ }^{13} \mathrm{C}$ NMR (75 MHz, $\left.\mathrm{C}_{6} \mathrm{D}_{6}, 30 / 31 \mathrm{C}\right): \delta$ 190.1, 145.1, 139.3, 130.2, 83.5 (2C), 82.0, 77.2, 72.6, 66.5, 51.7, 46.1, 42.0, 41.6, 36.8, 26.4 (3C), 25.4 (2C), 25.2 (2C), 18.5, 18.3, 16.9, -0.9 (3C), 3.6, -4.3; IR (film): 2953, 2931, 2858, 1658, 1543, 1249, 1141, $1085 \mathrm{~cm}^{-1}$; HRMS-FAB $(\mathrm{m} / \mathrm{z})$ : $[\mathrm{M}+\mathrm{H}]^{+}$calc'd for $\mathrm{C}_{31} \mathrm{H}_{57} \mathrm{BNO}_{6} \mathrm{Si}_{2}, 606.3818$; found, 606.3805; $[\alpha]^{19}{ }_{\mathrm{D}}-98.84^{\circ}\left(c 1.0, \mathrm{C}_{6} \mathrm{H}_{6}\right)$.
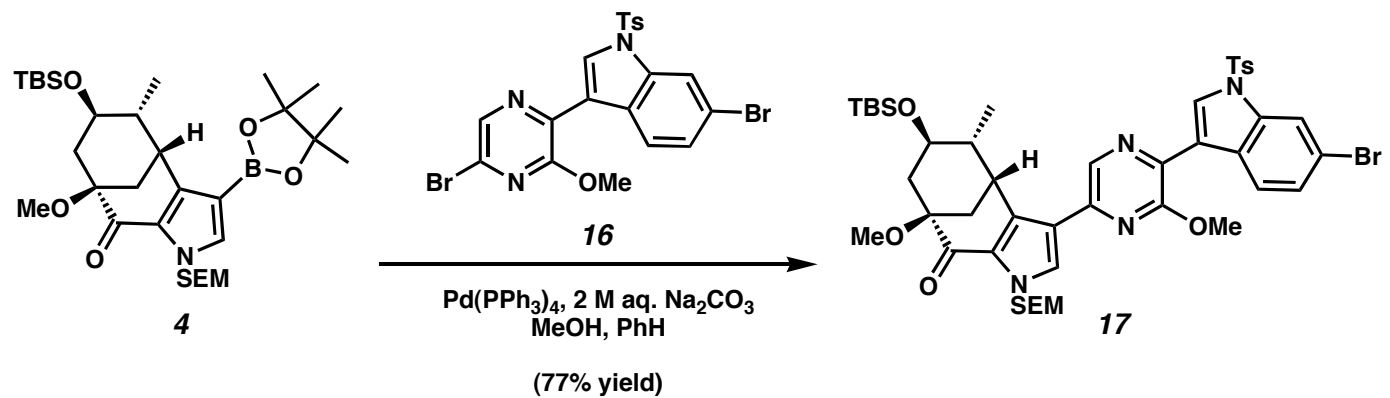

Suzuki Adduct 17. Bromopyrazine $\mathbf{1 6}^{7}$ (46.5 mg, $\left.0.087 \mathrm{mmol}\right)$, boronic ester 4 (35 mg, $0.058 \mathrm{mmol})$, benzene $(1.15 \mathrm{~mL})$, methanol $(231 \mu \mathrm{L}), 2 \mathrm{M}$ aq. $\mathrm{Na}_{2} \mathrm{CO}_{3}(96 \mu \mathrm{L})$, and tetrakis(triphenylphosphine)palladium(0) $(6.7 \mathrm{mg}, 0.0058 \mathrm{mmol})$ were combined and deoxygenated by sparging with argon for $5 \mathrm{~min}$. The reaction vessel was evacuated, purged with $\mathrm{N}_{2}$, sealed, heated to $50{ }^{\circ} \mathrm{C}$ for $65 \mathrm{~h}$, cooled to $23{ }^{\circ} \mathrm{C}$, then quenched by the addition of $\mathrm{Na}_{2} \mathrm{SO}_{4}$ (200 mg). Following filtration over a pad of silica gel (2:1 hexanes:EtOAc eluent) and evaporation to dryness under reduced pressure, the remaining residue was purified by flash chromatography (3:1 hexanes:EtOAc) to afford Suzuki adduct 17 (41.5 mg, 77\% yield) as a yellow oil. $\mathrm{R}_{f} 0.43$ (2:1 hexanes:EtOAc); ${ }^{1} \mathrm{H}$ NMR (300 MHz, $\left.\mathrm{CDCl}_{3}\right): \delta 8.61(\mathrm{~d}, J=8.5 \mathrm{~Hz}$, $1 \mathrm{H}), 8.45(\mathrm{~s}, 1 \mathrm{H}), 8.44(\mathrm{~s}, 1 \mathrm{H}), 8.16(\mathrm{~d}, J=1.5 \mathrm{~Hz}, 1 \mathrm{H}), 7.80(\mathrm{~d}, J=8.5 \mathrm{~Hz}, 2 \mathrm{H}), 7.59(\mathrm{~s}, 1 \mathrm{H})$, $7.40(\mathrm{dd}, J=8.5 \mathrm{~Hz}, 1.8 \mathrm{~Hz}, 1 \mathrm{H}), 7.23(\mathrm{~d}, J=7.9 \mathrm{~Hz}, 2 \mathrm{H}), 5.85$ (d, $J=10.0 \mathrm{~Hz}, 1 \mathrm{H}), 5.78(\mathrm{~d}, J=$ $10.0 \mathrm{~Hz}, 1 \mathrm{H}), 4.27-4.21(\mathrm{~m}, 1 \mathrm{H}), 4.19(\mathrm{~s}, 3 \mathrm{H}), 3.72-3.59(\mathrm{~m}, 2 \mathrm{H}), 3.34(\mathrm{~s}, 3 \mathrm{H}), 3.13-3.02(\mathrm{~m}$, 1H), 2.87-2.77 (m, 1H), $2.32(\mathrm{~s}, 3 \mathrm{H}), 2.22-2.12(\mathrm{~m}, 1 \mathrm{H}), 1.98-1.89(\mathrm{~m}, 1 \mathrm{H}), 1.82-1.72(\mathrm{~m}, 1 \mathrm{H})$, 1.67 (app. t, $J=11.7 \mathrm{~Hz}, 1 \mathrm{H}), 1.04-0.83(\mathrm{~m}, 2 \mathrm{H}), 0.78$ (s, 9H), $0.72(\mathrm{~d}, J=6.7 \mathrm{~Hz}, 3 \mathrm{H}),-0.02(\mathrm{~s}$, 9H), -0.09 (s, 3H), -0.16 (s, 3H); ${ }^{13} \mathrm{C}$ NMR (75 MHz, $\left.\mathrm{CDCl}_{3}, 44 / 45 \mathrm{C}\right): \delta$ 190.0, 156.2, 145.7, $143.6,136.9,135.7,135.5,135.0,132.7,130.3$ (2C), 130.2, 129.3, 128.8, 128.5, 127.3, 127.1 (2C), 125.3, 120.5, 119.0, 116.9, 116.4, 81.3, 77.2, 71.4, 66.7, 54.3, 51.6, 44.8, 41.8, 40.2, 34.8, 25.9 (3C), 21.8, 18.1, 16.1, -1.1 (3C), -4.0, -4.7; IR (film): 2952, 1660, 1555, 1372, 1372, 1190 ,

\footnotetext{
${ }^{7}$ Garg, N. K.; Sarpong, R.; Stoltz, B. M. J. Am. Chem. Soc. 2002, 124, 13179-13184.
} 
1140, $1089 \mathrm{~cm}^{-1}$; HRMS-FAB $(\mathrm{m} / \mathrm{z})$ : $[\mathrm{M}]^{+}$calc'd for $\mathrm{C}_{45} \mathrm{H}_{59} \mathrm{~N}_{4} \mathrm{O}_{7} \mathrm{Si}_{2} \mathrm{SBr}$, 934.2826; found, 934.2829; $[\alpha]^{21}+51.73^{\circ}\left(c 1.0, \mathrm{CHCl}_{3}\right)$.
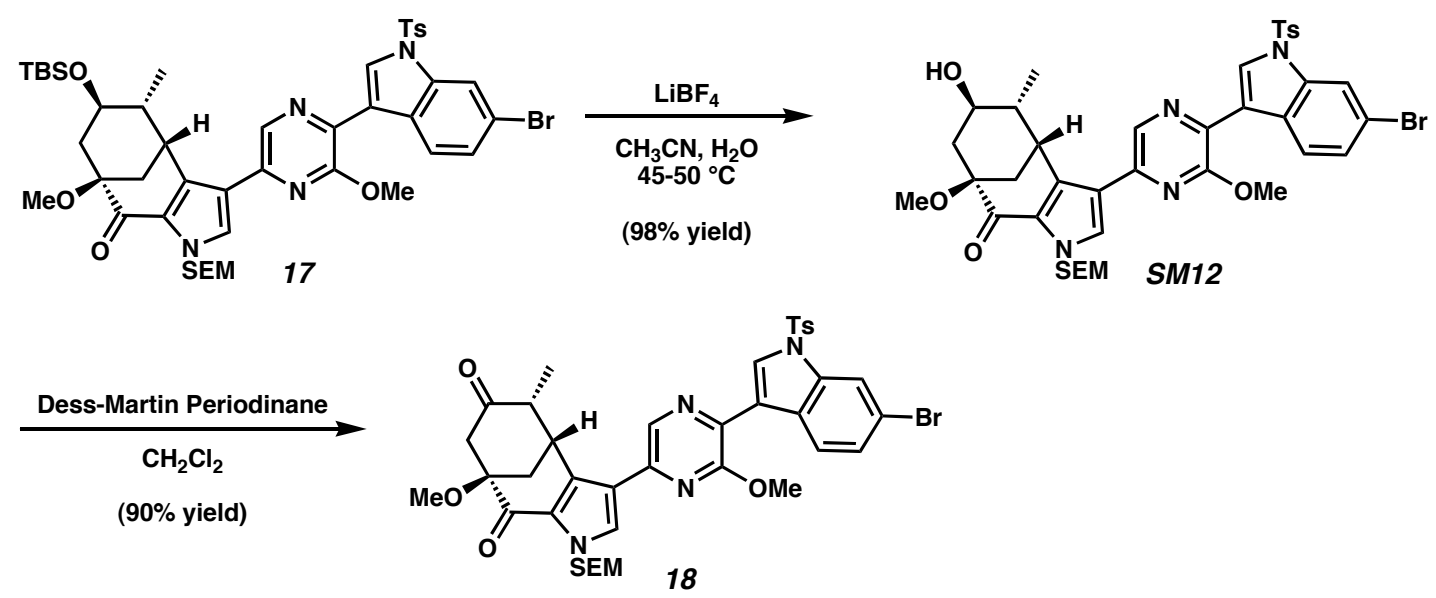

Ketone 18. Suzuki adduct $17(113 \mathrm{mg}, 0.121 \mathrm{mmol}), \mathrm{LiBF}_{4}(113 \mathrm{mg}, 1.21 \mathrm{mmol})$, acetonitrile $(6 \mathrm{~mL})$, and water $(600 \mu \mathrm{L})$ were heated to $45-50{ }^{\circ} \mathrm{C}$. After $9 \mathrm{~h}$, additional $\mathrm{LiBF}_{4}(30$ $\mathrm{mg}, 0.32 \mathrm{mmol}$ ) was introduced and heating was continued. After $6 \mathrm{~h}$, additional $\mathrm{LiBF}_{4}(35 \mathrm{mg}$, $0.32 \mathrm{mmol}$ ) was introduced and heating was continued for $16 \mathrm{~h}$. The reaction mixture was cooled to $23{ }^{\circ} \mathrm{C}$, quenched with $10 \%$ aq. citric acid $(10 \mathrm{~mL})$ and extracted with EtOAc $(3 \times 20 \mathrm{~mL})$. The combined organic layers were dried over $\mathrm{MgSO}_{4}$ and evaporated under reduced pressure. The crude product was purified by flash chromatography (3:1 EtOAc:hexanes) to yield alcohol SM12 (96.9 $\mathrm{mg}, 98 \%$ yield) as a yellow oil which was used in the subsequent step without further purification. $\mathrm{R}_{f}=0.44$ (3:1 EtOAc:hexanes).

To alcohol SM12 $(96 \mathrm{mg}, 0.117 \mathrm{mmol})$ in $\mathrm{CH}_{2} \mathrm{Cl}_{2}(2.0 \mathrm{~mL})$ at $23{ }^{\circ} \mathrm{C}$ was added DessMartin Periodinane $(74.3 \mathrm{mg}, 0.175 \mathrm{mmol})$. The mixture was stirred for $3 \mathrm{~min}$, quenched with a solution of saturated aq. $\mathrm{NaHCO}_{3}$ and saturated aq. $\mathrm{Na}_{2} \mathrm{~S}_{2} \mathrm{O}_{3}(1: 1,5 \mathrm{~mL})$, stirred for $5 \mathrm{~min}$, and extracted with EtOAc ( $3 \times 15 \mathrm{~mL})$. The combined organic layers were washed with brine (15 $\mathrm{mL}$ ), dried over $\mathrm{MgSO}_{4}$, and evaporated under reduced pressure. The crude product was purified by flash chromatography ( $1: 1$ hexanes:EtOAc) to yield ketone $\mathbf{1 8}(86 \mathrm{mg}, 90 \%$ yield) as a yellow foam. $\mathrm{R}_{f}=0.48\left(1: 1\right.$ hexanes:EtOAc); ${ }^{1} \mathrm{H}$ NMR $\left(300 \mathrm{MHz}, \mathrm{CDCl}_{3}\right): \delta 8.61(\mathrm{~d}, J=8.5 \mathrm{~Hz}, 1 \mathrm{H})$, 8.45 (s, 1H), $8.42(\mathrm{~s}, 1 \mathrm{H}), 8.18$ (d, $J=1.7 \mathrm{~Hz}, 1 \mathrm{H}), 7.81$ (d, $J=8.5 \mathrm{~Hz}, 2 \mathrm{H}), 7.56(\mathrm{~s}, 1 \mathrm{H}), 7.42$ (dd, $J=8.7 \mathrm{~Hz}, 1.8 \mathrm{~Hz}, 1 \mathrm{H}), 7.25$ (d, $J=7.7 \mathrm{~Hz}, 2 \mathrm{H}), 5.77$ (d, $J=10.5 \mathrm{~Hz}, 1 \mathrm{H}), 5.72$ (d, $J=10.2$ Hz, 1H), 4.62-4.56 (m, 1H), 4.20 (s, 3H), 3.57 (app. dt, $J=8.2 \mathrm{~Hz}, 1.8 \mathrm{~Hz}, 2 \mathrm{H}), 3.43$ (s, 3H), 
3.14-3.06 (m, 1H), 2.91-2.81 (m, 1H), $2.74(\mathrm{~s}, 2 \mathrm{H}), 2.40(\mathrm{dd}, J=12.5 \mathrm{~Hz}, 2.9 \mathrm{~Hz}, 1 \mathrm{H}), 2.34$ (s, $3 \mathrm{H}), 0.96-0.88(\mathrm{~m}, 2 \mathrm{H}), 0.78(\mathrm{~d}, J=6.6 \mathrm{~Hz}, 3 \mathrm{H}),-0.02(\mathrm{~s}, 9 \mathrm{H}) ;{ }^{13} \mathrm{C} \mathrm{NMR}\left(75 \mathrm{MHz}, \mathrm{CDCl}_{3}\right.$, 37/39 C): $\delta 207.2,188.0,156.1,145.7,143.2,136.3,135.7,134.9,132.6,130.7,130.3$ (2C), $128.8,128.4,127.3,127.1$ (2C), 125.4, 120.5, 119.0, 116.8, 116.3, 82.4, 77.1, 66.9, 54.3, 52.2, 52.0, 49.2, 40.2, 35.2, 21.8, 18.1, 12.2, -1.2 (3C); IR (film): 2950, 1716, 1664, 1557, 1373, 1190, 1178, $1090 \mathrm{~cm}^{-1}$; HRMS-FAB $(\mathrm{m} / z)$ : $[\mathrm{M}]^{+}$calc'd for $\mathrm{C}_{39} \mathrm{H}_{43} \mathrm{~N}_{4} \mathrm{O}_{7} \mathrm{SiSBr}$, 818.1805; found, 818.1836; $[\alpha]^{21}+71.61^{\circ}\left(c 1.0, \mathrm{CHCl}_{3}\right)$.
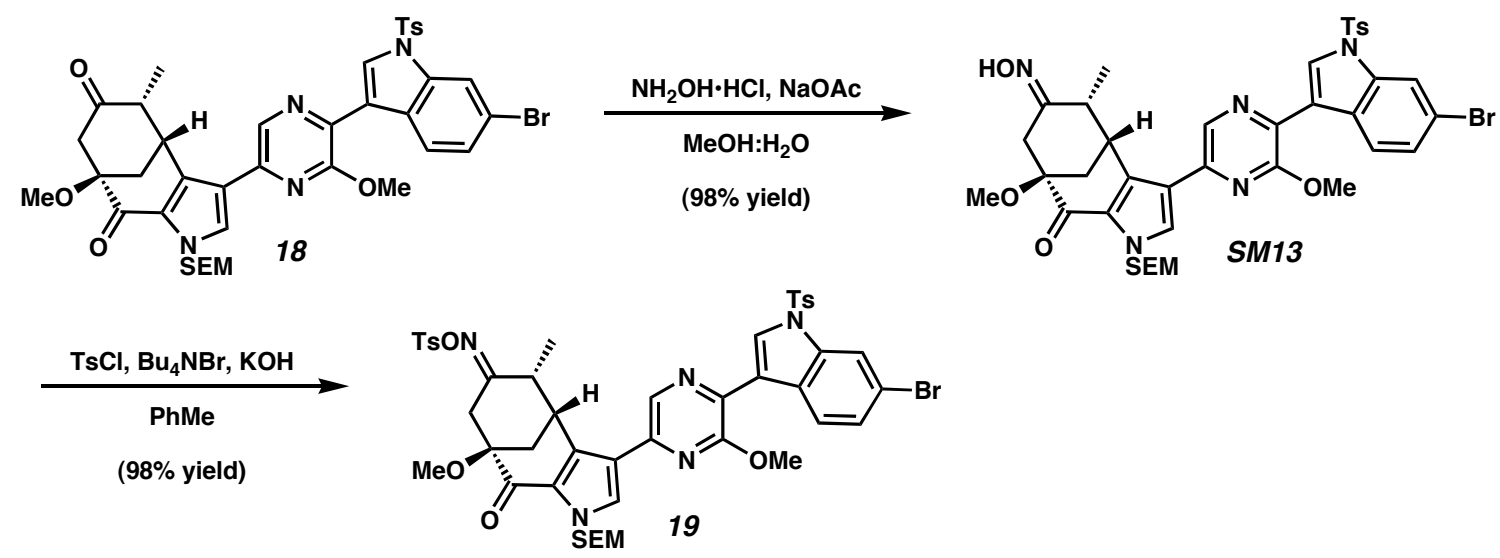

Tosyl Oxime 19. To ketone $18(50.0 \mathrm{mg}, 0.061 \mathrm{mmol}), \mathrm{NH}_{2} \mathrm{OH} \cdot \mathrm{HCl}(85 \mathrm{mg}, 1.22$ $\mathrm{mmol})$, and $\mathrm{NaOAc} \cdot 3 \mathrm{H}_{2} \mathrm{O}(125 \mathrm{mg}, 0.915 \mathrm{mmol})$ was added methanol $(2.5 \mathrm{~mL})$, followed by $\mathrm{H}_{2} \mathrm{O}(350 \mu \mathrm{L})$, then additional methanol $(5 \mathrm{~mL})$. The homogeneous solution was stirred at $23{ }^{\circ} \mathrm{C}$ for $8 \mathrm{~h}$ and the solvent was removed under reduced pressure. $\mathrm{H}_{2} \mathrm{O}(15 \mathrm{~mL})$ was added, and the resulting mixture was extracted with EtOAc $(3$ x $15 \mathrm{~mL})$. The combined organic layers were washed with brine $(15 \mathrm{~mL})$, dried over $\mathrm{MgSO}_{4}$, and evaporated under reduced pressure. The crude product was further purified by filtration over a plug of silica gel (EtOAc eluent) to yield oxime SM13 (50.1 mg, 98\% yield) as a yellow foam which was used without purification in the subsequent reaction. $\mathrm{R}_{f}=0.46$ (1:1 hexanes:EtOAc).

To a solution of oxime SM13 (20.0 mg, $0.0240 \mathrm{mmol})$, TsCl (14.0 mg, $0.0734 \mathrm{mmol})$, and $\mathrm{Bu}_{4} \mathrm{NBr}(1.0 \mathrm{mg}, 0.0031 \mathrm{mmol})$ in toluene $(2.0 \mathrm{~mL})$ at $0{ }^{\circ} \mathrm{C}$ was added $50 \%$ aq. $\mathrm{KOH}(310$ $\mu \mathrm{L})$. The reaction mixture was stirred at $0{ }^{\circ} \mathrm{C}$ for $2 \mathrm{~h}$, quenched with ice-cold $\mathrm{H}_{2} \mathrm{O}(1.5 \mathrm{~mL})$ and extracted with ice-cold EtOAc $(5 \times 1 \mathrm{~mL})$. The combined organic layers were washed with brine $(1 \mathrm{~mL})$, dried by passage over a plug of silica gel (EtOAc eluent), and evaporated under reduced 
pressure. The crude product was purified by flash chromatography (1:1 hexanes:EtOAc) to yield tosyl oxime 19 (23.3 mg, 98\% yield) as a yellow foam. $\mathrm{R}_{f}=0.48$ (1:1 hexanes:EtOAc); ${ }^{1} \mathrm{H}$ NMR $\left(300 \mathrm{MHz}, \mathrm{CDCl}_{3}\right): \delta 8.63(\mathrm{~d}, J=8.5 \mathrm{~Hz}, 1 \mathrm{H}), 8.46(\mathrm{~s}, 1 \mathrm{H}), 8.41(\mathrm{~s}, 1 \mathrm{H}), 8.19(\mathrm{~d}, J=1.4 \mathrm{~Hz}$, 1H), $7.81(\mathrm{~d}, J=8.3 \mathrm{~Hz}, 2 \mathrm{H}), 7.65$ (d, $J=8.0 \mathrm{~Hz}, 2 \mathrm{H}), 7.51$ (s, 1H), 7.44 (dd, $J=8.7 \mathrm{~Hz}, 1.5 \mathrm{~Hz}$, 1H), 7.28-7.19 (comp. m, 4H), 5.87 (d, $J=10.2 \mathrm{~Hz}, 1 \mathrm{H}$ ), 5.42 (d, $J=10.2 \mathrm{~Hz}, 1 \mathrm{H}$ ), 4.45-4.43 (m, 1H), 4.20 (s, 3H), 3.67-3.53 (comp. m, 3H), 3.38 (s, 3H), 2.98-2.89 (m, 1H), 2.87-2.77 (m, 1H), 2.42 (s, 3H), 2.35 (s, 3H), 2.12 (d, $J=14.0 \mathrm{~Hz}, 2 \mathrm{H}), 1.05-0.85$ (m, 2H), 0.78 (d, $J=6.6 \mathrm{~Hz}$, $3 \mathrm{H}),-0.02(\mathrm{~s}, 9 \mathrm{H}) ;{ }^{13} \mathrm{C}$ NMR $\left(75 \mathrm{MHz}, \mathrm{CDCl}_{3}\right): \delta 187.2,165.8,156.3,145.8,144.8,143.5$, 135.8, 135.7, 135.3 135.0, 132.9, 132.6, 130.4 (2C), 129.9, 129.4 (2C), 129.1 (2C), 128.9, 128.4, 128.0, 127.5, 127.2 (2C), 125.3, 120.3, 119.2, 116.8, 116.5, 80.8, 77.4, 67.2, 54.4, 52.2, 42.5, 40.3, 36.5, 36.2, 21.9, 21.9, 18.1, 13.7, -1.1 (3C); IR (film): 2946, 1665, 1555, 1373, 1191, 1178 , $1140 \mathrm{~cm}^{-1}$; HRMS-FAB $(\mathrm{m} / \mathrm{z})$ : $[\mathrm{M}]^{+}$calc'd for $\mathrm{C}_{46} \mathrm{H}_{50} \mathrm{~N}_{5} \mathrm{O}_{9} \mathrm{SiS}_{2} \mathrm{Br}$, 987.2002; found, 987.2038; $[\alpha]^{20}{ }_{\mathrm{D}}+139.01^{\circ}\left(c 1.0, \mathrm{CHCl}_{3}\right)$.
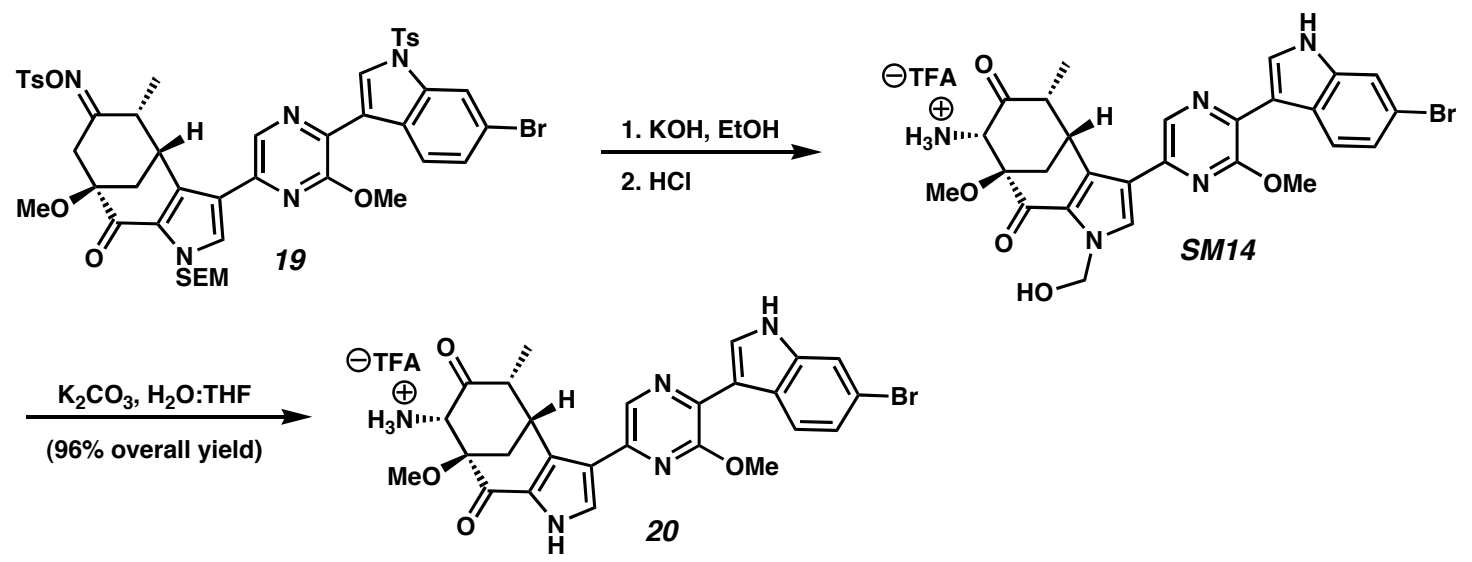

Amino Ketone 20. To a stirred solution of tosyl oxime 19 (23.3 $\mathrm{mg}, 0.0236 \mathrm{mmol})$ in EtOH $(3.5 \mathrm{~mL})$ at $0{ }^{\circ} \mathrm{C}$ was added $50 \%$ aq. $\mathrm{KOH}(450 \mu \mathrm{L})$ dropwise over $1 \mathrm{~min}$. The reaction mixture was stirred at $0{ }^{\circ} \mathrm{C}$ for $3 \mathrm{~h}$, then $6 \mathrm{~N}$ aq. $\mathrm{HCl}(5 \mathrm{~mL})$ was added. The reaction mixture was heated to $60^{\circ} \mathrm{C}$ for $10 \mathrm{~h}$, cooled to $23{ }^{\circ} \mathrm{C}$, and purified by reversed-phase filtration through a Sep-Pak column: loaded with water containing $0.1 \%$ (w/v) TFA, washed with $15 \%$ acetonitrile:water containing $0.1 \%(\mathrm{w} / \mathrm{v})$ TFA to remove salts, then $70 \%$ acetonitrile:water containing $0.1 \%(\mathrm{w} / \mathrm{v})$ TFA to collect the crude product. The solvents were removed under reduced pressure to afford hemiaminal SM14, which was used immediately in the subsequent reaction. 
Hemiaminal 14 and $\mathrm{K}_{2} \mathrm{CO}_{3}(60 \mathrm{mg}, 0.434 \mathrm{mmol})$ in THF $(2 \mathrm{~mL})$ at $23{ }^{\circ} \mathrm{C}$ was added $\mathrm{H}_{2} \mathrm{O}$ $(200 \mu \mathrm{L})$. The reaction mixture was stirred for $10 \mathrm{~min}$, then purified by reversed-phase filtration through a Sep-Pak column: loaded with water containing $0.1 \%$ (w/v) TFA, washed with $10 \%$ acetonitrile:water containing $0.1 \%(\mathrm{w} / \mathrm{v})$ TFA to remove salts, then $70 \%$ acetonitrile:water containing $0.1 \%(\mathrm{w} / \mathrm{v})$ TFA to collect the crude product. After removal of solvents under reduced pressure, the crude material was further purified by reversed-phased HPLC. Concentration under reduced pressure provided amino ketone 20 ( $15.0 \mathrm{mg}, 96 \%$ yield) as an orange/red oil. ${ }^{1} \mathrm{H}$ NMR (300 MHz, $\left.\mathrm{CD}_{3} \mathrm{OD}\right): \delta 8.60(\mathrm{~d}, J=8.5 \mathrm{~Hz}, 1 \mathrm{H}), 8.53(\mathrm{~s}, 1 \mathrm{H}), 8.23$ (s, 1H), $7.81(\mathrm{~s}, 1 \mathrm{H}), 7.61$ (d, $J=1.4 \mathrm{~Hz}, 1 \mathrm{H}), 7.25(\mathrm{dd}, J=8.7 \mathrm{~Hz}, 1.8 \mathrm{~Hz}, 1 \mathrm{H}), 4.82-4.78(\mathrm{~m}, 1 \mathrm{H}), 4.46(\mathrm{~s}, 1 \mathrm{H}), 4.21(\mathrm{~s}, 3 \mathrm{H})$, 3.47 (s, 3H), 3.41-3.30 (m, 1H), $3.26(\mathrm{dd}, J=12.9 \mathrm{~Hz}, 3.9 \mathrm{~Hz}, 1 \mathrm{H}), 2.61$ (dd, $J=12.9 \mathrm{~Hz}, 3.0$ $\mathrm{Hz}, 1 \mathrm{H}), 0.88(\mathrm{~d}, J=6.6 \mathrm{~Hz}, 3 \mathrm{H}) ;{ }^{13} \mathrm{C}$ NMR $\left(75 \mathrm{MHz}, \mathrm{CD}_{3} \mathrm{OD}, 25 / 26 \mathrm{C}\right): \delta 203.5,183.3,156.8$, 142.4, 139.9, 139.1, 136.3, 133.4, 130.7, 129.9, 129.6, 126.9, 125.5, 124.5, 123.1, 116.9, 115.4, 112.6, 84.3, 66.0, 54.5, 52.9, 40.4, 36.6, 12.2; IR (film): 3156 (br), 2935, 1674, 1531, 1447, 1409, 1203, $1135 \mathrm{~cm}^{-1}$; HRMS-FAB $(\mathrm{m} / \mathrm{z})$ : $[\mathrm{M}+\mathrm{H}]^{+}$calc'd for $\mathrm{C}_{26} \mathrm{H}_{25} \mathrm{~N}_{5} \mathrm{O}_{4} \mathrm{Br}, 550.1090$; found, $550.1071 ;[\alpha]^{20}{ }_{D}+99.19^{\circ}(c 0.87, \mathrm{MeOH})$.

The relative stereochemistry of deprotected amino ketone $\mathbf{2 0}$ was determined by NOE experiments. Medium strength NOE interactions were observed as indicated below. Analogous NOE interactions were observed for hemiaminal SM14 and deprotected amino ketone SM15.

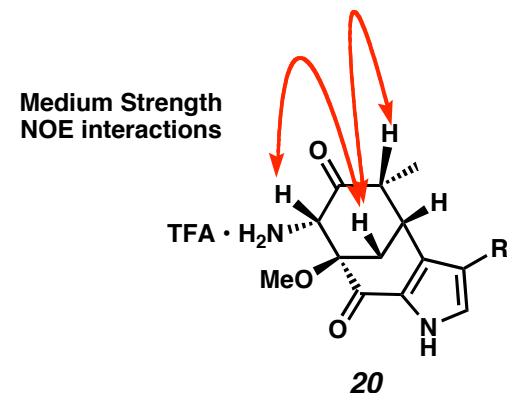



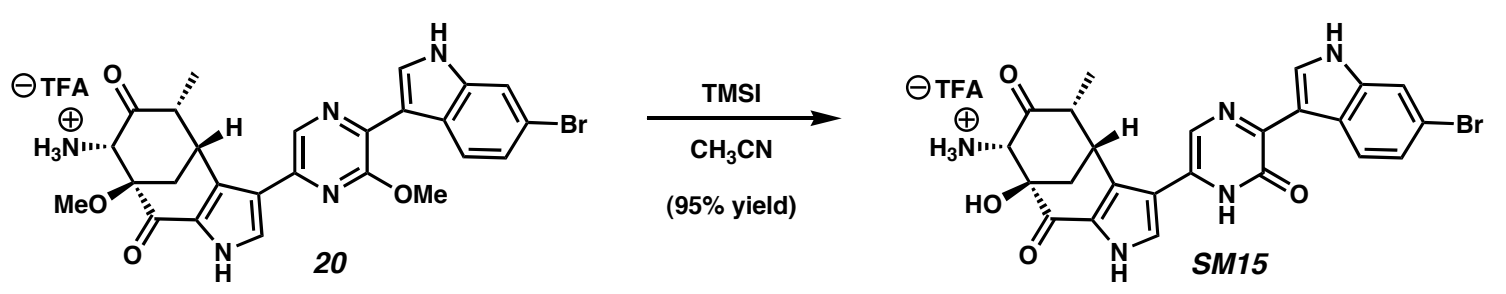

Deprotected Amino Ketone SM15. To a stirred solution of amino ketone 20 (7.5 mg, $0.0113 \mathrm{mmol})$ in $\mathrm{MeCN}(1 \mathrm{~mL})$ at $0{ }^{\circ} \mathrm{C}$ was added TMSI $(500 \mu \mathrm{L}, 3.51 \mathrm{mmol})$ dropwise over 30 sec. The reaction mixture was heated to $60{ }^{\circ} \mathrm{C}$ for $48 \mathrm{~h}$, cooled to $0{ }^{\circ} \mathrm{C}$, then transferred dropwise into a chilled solution $\left(0^{\circ} \mathrm{C}\right)$ of saturated aqueous sodium metabisulfite $(5 \mathrm{~mL})$. The mixture was diluted with $6 \mathrm{~N} \mathrm{HCl}(15 \mathrm{~mL})$, stirred at $0{ }^{\circ} \mathrm{C}$ for $20 \mathrm{~min}$, then purified by reversed-phase filtration through a Sep-Pak column: loaded with water containing $0.1 \%(\mathrm{w} / \mathrm{v}) \mathrm{TFA}$, washed with $1 \mathrm{~N} \mathrm{HCl}, 10 \%$ acetonitrile:water containing $0.1 \%(\mathrm{w} / \mathrm{v})$ TFA to remove salts, then $60 \%$ acetonitrile:water containing $0.1 \%(\mathrm{w} / \mathrm{v})$ TFA to collect the crude product. After removal of solvents under reduced pressure, the crude material was further purified by reversed-phase HPLC. Concentration under reduced pressure provided deprotected amino ketone SM15 (6.8 mg, 95\% yield) as an orange/red oil. ${ }^{1} \mathrm{H}$ NMR (300 MHz, $\left.\mathrm{CD}_{3} \mathrm{OD}\right): \delta 8.69(\mathrm{~s}, 1 \mathrm{H}), 8.59$ (d, $J=$ $8.5 \mathrm{~Hz}, 1 \mathrm{H}), 7.69$ (s, 1H), 7.61 (d, $J=1.7 \mathrm{~Hz}, 1 \mathrm{H}), 7.57$ (s, 1H), 7.27 (dd, $J=8.5 \mathrm{~Hz}, 1.7 \mathrm{~Hz}$, 1H), 4.40 (s, 1H), 4.06-3.98 (m, 1H), 3.31-3.21 (m, 1H), 2.87 (dd, J=13.2 Hz, 3.3 Hz, 1H), 2.79 $(\mathrm{dd}, J=13.1 \mathrm{~Hz}, 2.9 \mathrm{~Hz}, 1 \mathrm{H}), 0.85(\mathrm{~d}, J=6.6 \mathrm{~Hz}, 3 \mathrm{H}) ;{ }^{13} \mathrm{C} \mathrm{NMR}\left(75 \mathrm{MHz}, \mathrm{CD}_{3} \mathrm{OD}, 23 / 24 \mathrm{C}\right): \delta$ 203.4, 186.0, 157.4, 139.1, 136.3, 132.5, 132.4, 130.2, 130.1, 128.2, 126.7, 126.7, 125.6, 124.9, 117.1, 115.4, 113.6, 79.3, 67.1, 49.6, 45.5, 36.7, 12.3; IR (film): 3164 (br), 2927, 1674, 1451, 1207, $1143 \mathrm{~cm}^{-1}$; HRMS-FAB $(\mathrm{m} / z)$ : $[\mathrm{M}+\mathrm{H}]^{+}$calc'd for $\mathrm{C}_{24} \mathrm{H}_{21} \mathrm{~N}_{5} \mathrm{O}_{4} \mathrm{Br}, 522.0777$; found, 522.0783; $[\alpha]_{\mathrm{D}}^{22}+86.88^{\circ}(c 0.33, \mathrm{MeOH})$.
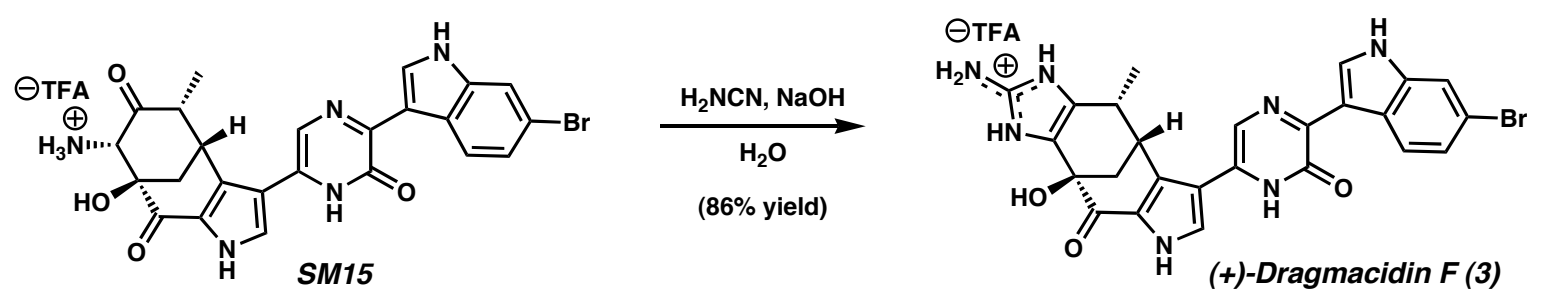

(+)-Dragmacidin F (3). To deprotected amino ketone SM15 (3.6 mg, $0.0056 \mathrm{mmol}$ ) and cyanamide $(120 \mathrm{mg}, 2.86 \mathrm{mmol})$ in $\mathrm{H}_{2} \mathrm{O}(2 \mathrm{~mL})$ at $23{ }^{\circ} \mathrm{C}$ was added $10 \%$ aq. $\mathrm{NaOH}(80 \mu \mathrm{L})$. The reaction mixture was heated to $60^{\circ} \mathrm{C}$ for $2 \mathrm{~h}$, cooled to $23{ }^{\circ} \mathrm{C}$, then purified by reversed-phase 
filtration through a Sep-Pak column: loaded with water containing $0.1 \%(\mathrm{w} / \mathrm{v}) \mathrm{TFA}$, washed with $10 \%$ acetonitrile:water containing $0.1 \%(\mathrm{w} / \mathrm{v})$ TFA to remove salts, then $60 \%$ acetonitrile:water containing $0.1 \%(\mathrm{w} / \mathrm{v})$ TFA to collect the crude product. After removal of solvents under reduced pressure, the product was further purified by reversed-phase HPLC. Concentration under reduced pressure afforded (+)-Dragmacidin F (3, $3.2 \mathrm{mg}, 86 \%$ yield) as an orange/red oil. ${ }^{1} \mathrm{H}$ NMR (600 $\left.\mathrm{MHz}, \mathrm{CD}_{3} \mathrm{OD}\right): \delta 8.69(\mathrm{~s}, 1 \mathrm{H}), 8.59(\mathrm{~d}, J=8.7 \mathrm{~Hz}, 1 \mathrm{H}), 7.68(\mathrm{~s}, 1 \mathrm{H}), 7.60(\mathrm{~s}, 1 \mathrm{H}), 7.47(\mathrm{~s}, 1 \mathrm{H})$, $7.26(\mathrm{~d}, J=8.7 \mathrm{~Hz}, 1 \mathrm{H}), 4.12(\mathrm{br} \mathrm{s}, 1 \mathrm{H}), 3.40-3.34$ (m, 1H), 2.73 (dd, $J=12.0 \mathrm{~Hz}, 2.9 \mathrm{~Hz}, 1 \mathrm{H})$, $2.45(\mathrm{~d}, J=11.6 \mathrm{~Hz}, 1 \mathrm{H}), 0.92(\mathrm{~d}, J=7.0 \mathrm{~Hz}, 3 \mathrm{H}) ;{ }^{13} \mathrm{C} \mathrm{NMR}\left(125 \mathrm{MHz}, \mathrm{CD}_{3} \mathrm{OD}, 22 / 25 \mathrm{C}\right): \delta$ $188.5,157.5,149.6,139.1,132.6,132.4,128.5,128.4$, 126.7, 126.2, 125.6, 124.9, 124.8, 123.3, 117.1, 115.4, 113.7, 72.8, 45.3, 36.9, 33.3, 15.9; IR (film): 3175 (br), 2925, 1679, 1637, 1205, $1141 \mathrm{~cm}^{-1}$; UV $(\mathrm{MeOH}) \lambda_{\max }$ 283, $389 \mathrm{~nm}$; HRMS-FAB $(\mathrm{m} / \mathrm{z}):[\mathrm{M}+\mathrm{H}]^{+}$calc'd for $\mathrm{C}_{25} \mathrm{H}_{21} \mathrm{~N}_{7} \mathrm{O}_{3} \mathrm{Br}$, 546.0889; found, 546.0883; $[\alpha]^{23}{ }_{\mathrm{D}}+146.21^{\circ}(c 0.45, \mathrm{MeOH})$. 
(+)-Dragmacidin F NMR Comparison Table ${ }^{8}$

\begin{tabular}{|lc|cc|}
\hline \multicolumn{4}{|c|}{${ }^{1}$ H ppm (CD $\mathbf{~ O D ) ~}$} \\
\hline \multicolumn{3}{|c|}{ Natural $(600 \mathrm{MHz})$} & \multicolumn{3}{|c|}{ Synthetic $(600 \mathrm{MHz})$} \\
\hline 8.73 & $\mathrm{~s}$ & 8.69 & $\mathrm{~s}$ \\
8.61 & $\mathrm{~d}, 8.3$ & 8.59 & $\mathrm{~d}, 8.7$ \\
7.74 & $\mathrm{~s}$ & 7.68 & $\mathrm{~s}$ \\
7.65 & $\mathrm{~s}$ & 7.60 & $\mathrm{~s}$ \\
7.56 & $\mathrm{~s}$ & 7.47 & $\mathrm{~s}$ \\
7.27 & $\mathrm{dd}, 8.3,1.8$ & 7.26 & $\mathrm{~d}, 8.7$ \\
4.16 & $\mathrm{br} \mathrm{s}$ & 4.12 & $\mathrm{br} \mathrm{s}$ \\
3.38 & $\mathrm{q}, 7.0$ & 3.37 & $\mathrm{~m}$ \\
2.76 & $\mathrm{dd}, 11.8,3.50$ & 2.73 & $\mathrm{dd}, 12.0,2.9$ \\
2.49 & br d, 11.8 & 2.45 & $\mathrm{~d}, 11.6$ \\
0.93 & $\mathrm{~d}, 7.0(3 \mathrm{H})$ & 0.92 & $\mathrm{~d}, 7.0(3 \mathrm{H})$ \\
\hline
\end{tabular}

\begin{tabular}{|c|c|}
\hline \multicolumn{2}{|c|}{${ }^{13} \mathrm{C} \mathrm{ppm}\left(\mathrm{CD}_{3} \mathrm{OD}\right)$} \\
\hline Natural $(150 \mathrm{MHz})$ & Synthetic $(125 \mathrm{MHz})$ \\
\hline 189.0 & 188.5 \\
\hline 157.2 & 157.5 \\
\hline 149.6 & 149.6 \\
\hline 149.4 & - \\
\hline 138.8 & 139.1 \\
\hline 133.0 & 132.6 \\
\hline 132.2 & 132.4 \\
\hline 128.8 & 128.5 \\
\hline 128.1 & 128.4 \\
\hline 126.4 & 126.7 \\
\hline 125.9 & 126.2 \\
\hline 125.3 & 125.6 \\
\hline 125.0 & 124.9 \\
\hline 124.6 & 124.8 \\
\hline 123.1 & 123.3 \\
\hline 117.2 & 117.1 \\
\hline 116.8 & - \\
\hline 115.3 & 115.4 \\
\hline 113.3 & - \\
\hline 113.3 & 113.7 \\
\hline 73.1 & 72.8 \\
\hline 45.0 & 45.3 \\
\hline 36.8 & 36.9 \\
\hline 33.1 & 33.3 \\
\hline 15.8 & 15.9 \\
\hline
\end{tabular}

\footnotetext{
${ }^{8}$ Natural ${ }^{13} \mathrm{C}$ - and ${ }^{1} \mathrm{H}-\mathrm{NMR}$ data have been reproduced from the isolation paper, see: Cutignano, A.; Bifulco, G.; Bruno, I.; Casapullo, A.; Gomez-Paloma, L.; Riccio, R. Tetrahedron 2000, 56, 3743-3748.
} 
(+)-Dragmacidin F NMR Comparison Table ${ }^{8}$

\begin{tabular}{|c|c|c|c|c|c|}
\hline \multicolumn{6}{|c|}{${ }^{1} \mathrm{H}$ ppm $\left(\mathrm{DMSO}-\boldsymbol{d}_{\boldsymbol{6}}\right)^{9}$} \\
\hline \multicolumn{2}{|c|}{$\begin{array}{c}\text { Natural } \\
(600 \mathrm{MHz})\end{array}$} & \multicolumn{2}{|c|}{$\begin{array}{l}\text { Synthetic } \\
(500 \mathrm{MHz})\end{array}$} & \multicolumn{2}{|c|}{$\begin{array}{c}\text { Synthetic }+\mathrm{D}_{2} \mathrm{O}^{10} \\
(500 \mathrm{MHz})\end{array}$} \\
\hline 8.71 & $\mathrm{~s}$ & 8.77 & $\mathrm{~s}$ & 8.71 & $\mathrm{~s}$ \\
\hline 8.54 & d, 8.6 & 8.56 & d, 8.3 & 8.54 & d, 8.5 \\
\hline 7.68 & $\mathrm{~s}$ & 7.67 & d, 2.3 & 7.68 & $\mathrm{~d}, 1.8$ \\
\hline 7.52 & s & 7.57 & brs & 7.59 & brs \\
\hline 7.52 & $\mathrm{~s}$ & 7.54 & brs & 7.52 & brs \\
\hline 7.25 & br d, 8.6 & 7.28 & $\mathrm{dd}, 8.8,2.0$ & 7.28 & $\mathrm{dd}, 8.2,1.5$ \\
\hline 6.09 & & 6.00 & br s & - & see $^{12}$ \\
\hline 4.01 & br s & 4.03 & brs & 4.03 & br s \\
\hline 3.27 & $\mathrm{q}, 7.0$ & - & $\operatorname{see}^{13}$ & 3.28 & $\mathrm{~m}$ \\
\hline 2.53 & br d, 10.9 & 2.57 & $\mathrm{dd}, 12.2,3.9$ & 2.57 & $\mathrm{dd}, 11.9,3.7$ \\
\hline 2.26 & br d, 10.9 & 2.28 & $\mathrm{dd}, 12.0,2.2$ & 2.28 & $\mathrm{dd}, 12.1,2.0$ \\
\hline 0.78 & d, $6.7(3 \mathrm{H})$ & 0.78 & $\mathrm{~d}, 7.3(3 \mathrm{H})$ & 0.75 & $\mathrm{~d}, 7.0(3 \mathrm{H})$ \\
\hline
\end{tabular}

\begin{tabular}{|c|c|c|}
\hline \multicolumn{3}{|c|}{${ }^{\mathbf{1 3}} \mathbf{C}$ ppm (DMSO- $\boldsymbol{d}_{\mathbf{6}}$ ) } \\
\hline $\begin{array}{c}\text { Natural } \\
(150 \mathrm{MHz})\end{array}$ & $\begin{array}{c}\text { Synthetic } \\
(125 \mathrm{MHz})\end{array}$ & $\mathbf{\Delta}^{11}$ \\
\hline 188.9 & 187.0 & 1.9 \\
156.9 & 155.1 & 1.8 \\
149.6 & 147.6 & 2.0 \\
149.6 & - & \\
139.0 & 137.2 & 1.8 \\
132.9 & 131.2 & 1.7 \\
132.3 & 130.7 & 1.6 \\
132.3 & - & \\
128.8 & 127.1 & 1.7 \\
128.7 & 126.9 & 1.8 \\
126.7 & 124.9 & 1.8 \\
126.0 & 124.2 & 1.8 \\
125.1 & 123.9 & 1.2 \\
124.8 & 123.1 & 1.7 \\
122.7 & 121.2 & 1.5 \\
117.2 & - & \\
116.5 & 114.8 & 1.7 \\
116.2 & 114.3 & 1.9 \\
113.4 & 111.7 & 1.7 \\
110.9 & - & \\
72.9 & 71.1 & 1.8 \\
45.1 & 43.5 & 1.6 \\
36.4 & 34.6 & 1.8 \\
33.0 & 31.2 & 1.8 \\
16.8 & 14.9 & 1.9 \\
\hline Avg. Difference (ppm): & 1.7 \\
\hline & & \\
\hline
\end{tabular}

\footnotetext{
${ }^{9} \mathrm{NH}$ protons have been omitted from the table. See attached spectra in DMSO-d6. Note: NH protons appear at slightly different $\delta(\mathrm{ppm})$ than reported by the isolation chemists. ${ }^{8} \mathrm{We}$ attribute this to differences in sample concentrations, and counterion effects (natural: counterion = unknown; synthetic: counterion $=$ TFA).

${ }^{10}$ One drop of $\mathrm{D}_{2} \mathrm{O}$ was added to an NMR tube containing synthetic (+)-dragmacidin F in DMSO- $d_{6}$ and the sample was allowed to stand for 30 minutes at $23{ }^{\circ} \mathrm{C}$.

${ }^{11}$ There is clearly a discrepancy of $\sim 1.7 \mathrm{ppm}$ in the ${ }^{13} \mathrm{C}$ NMR data between the synthetic and natural samples of dragmacidin $\mathrm{F}$. This is likely due to the differences in the deuterium referencing values. The deuterium signal for the synthetic sample of dragmacidin F (in DMSO- $d_{6}$ ) was referenced to $39.51 \mathrm{ppm}$ in accord with Cambridge Isotope Laboratories, Inc.

${ }^{12}$ Proton exchanged for deuterium $(\mathrm{OH} \rightarrow \mathrm{OD})$.

${ }^{13}$ Signal obscured by $\mathrm{H}_{2} \mathrm{O}$.
} 


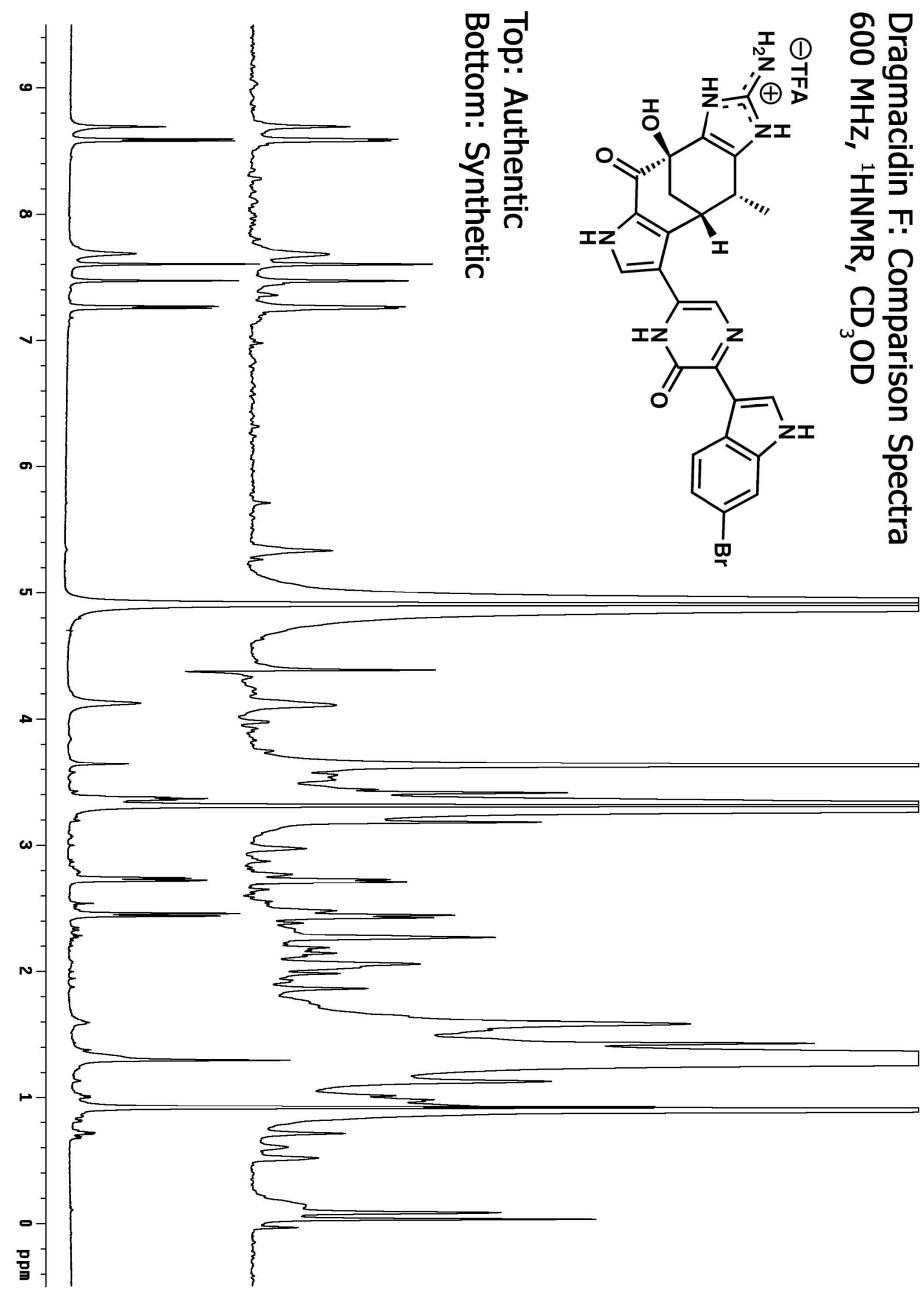




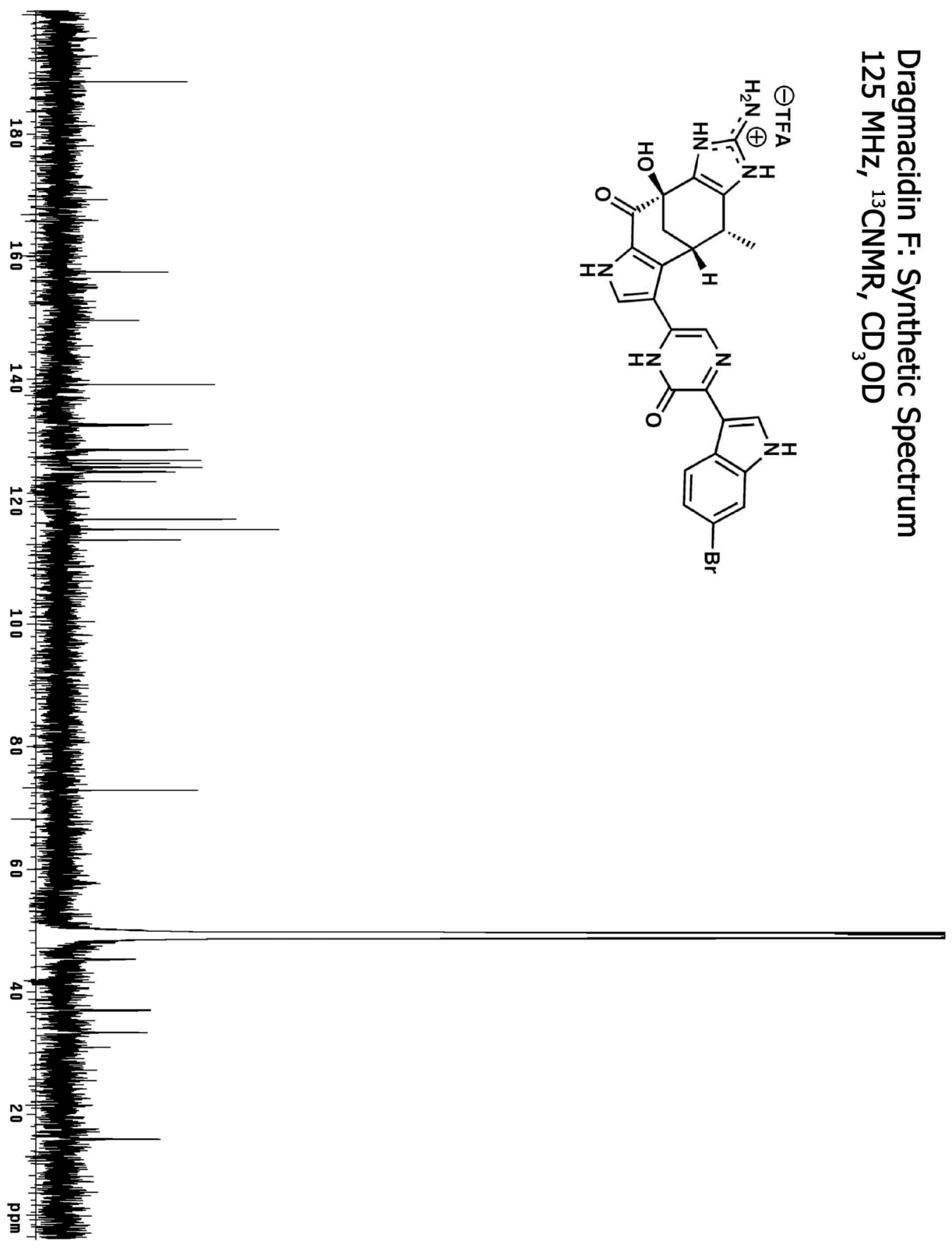




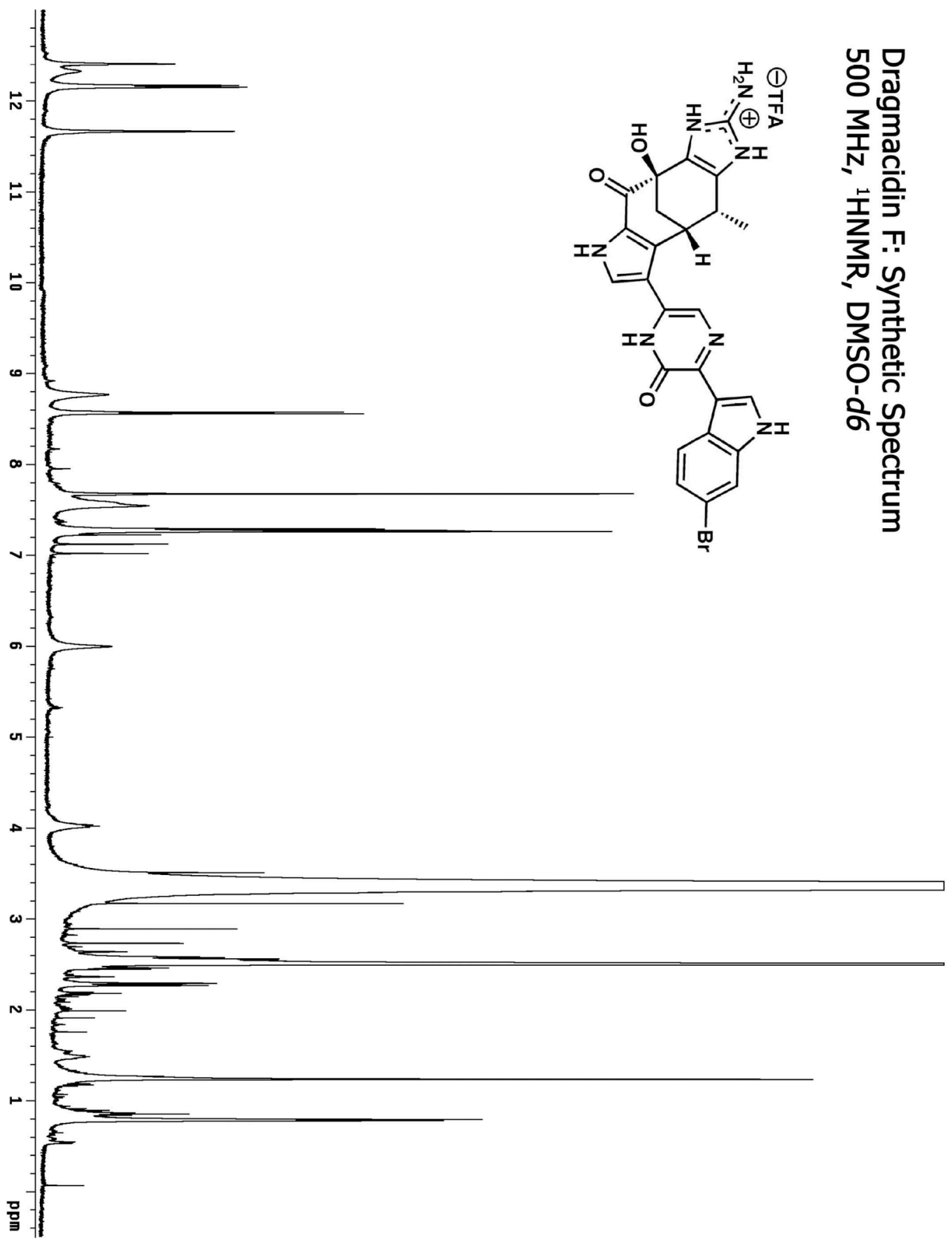




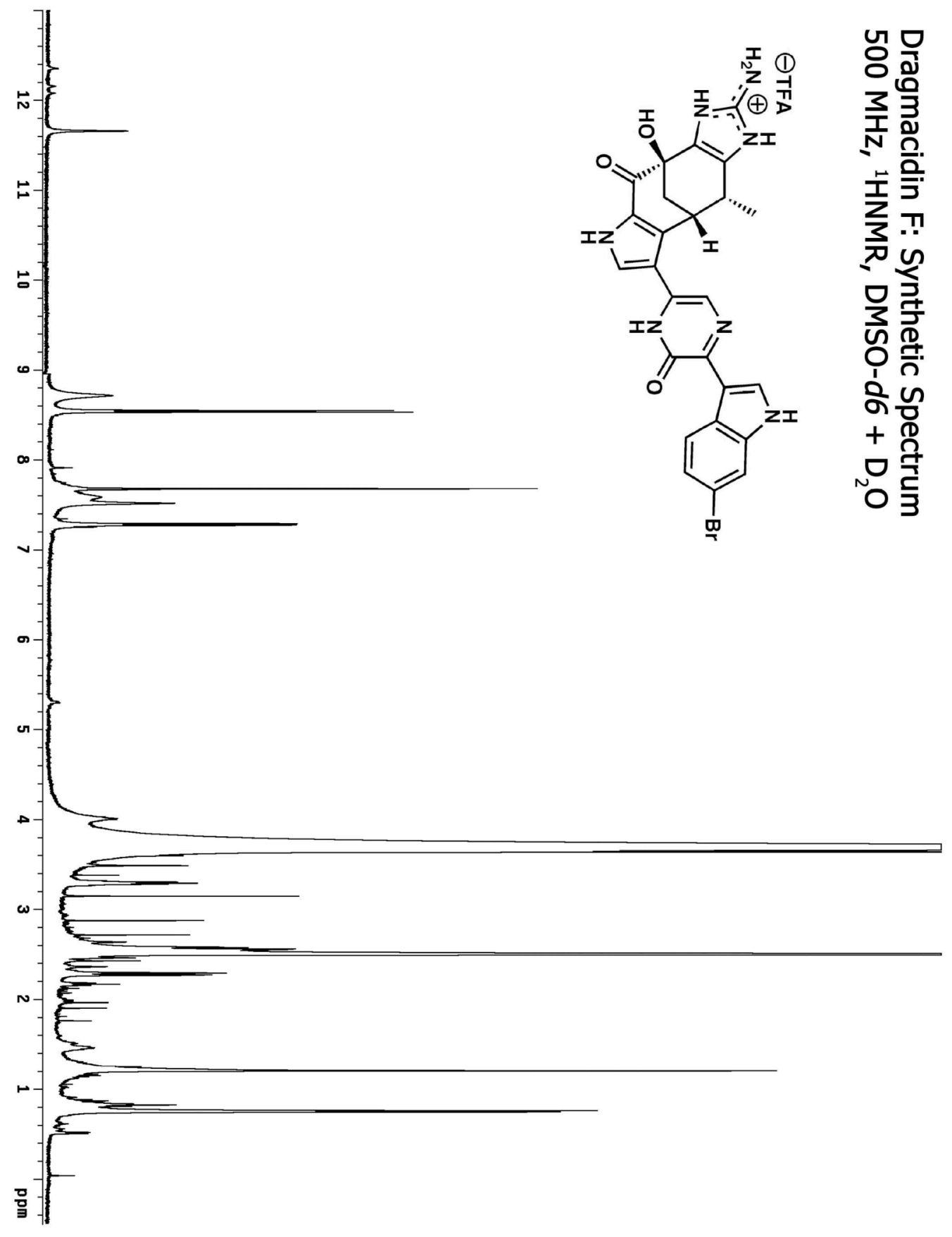




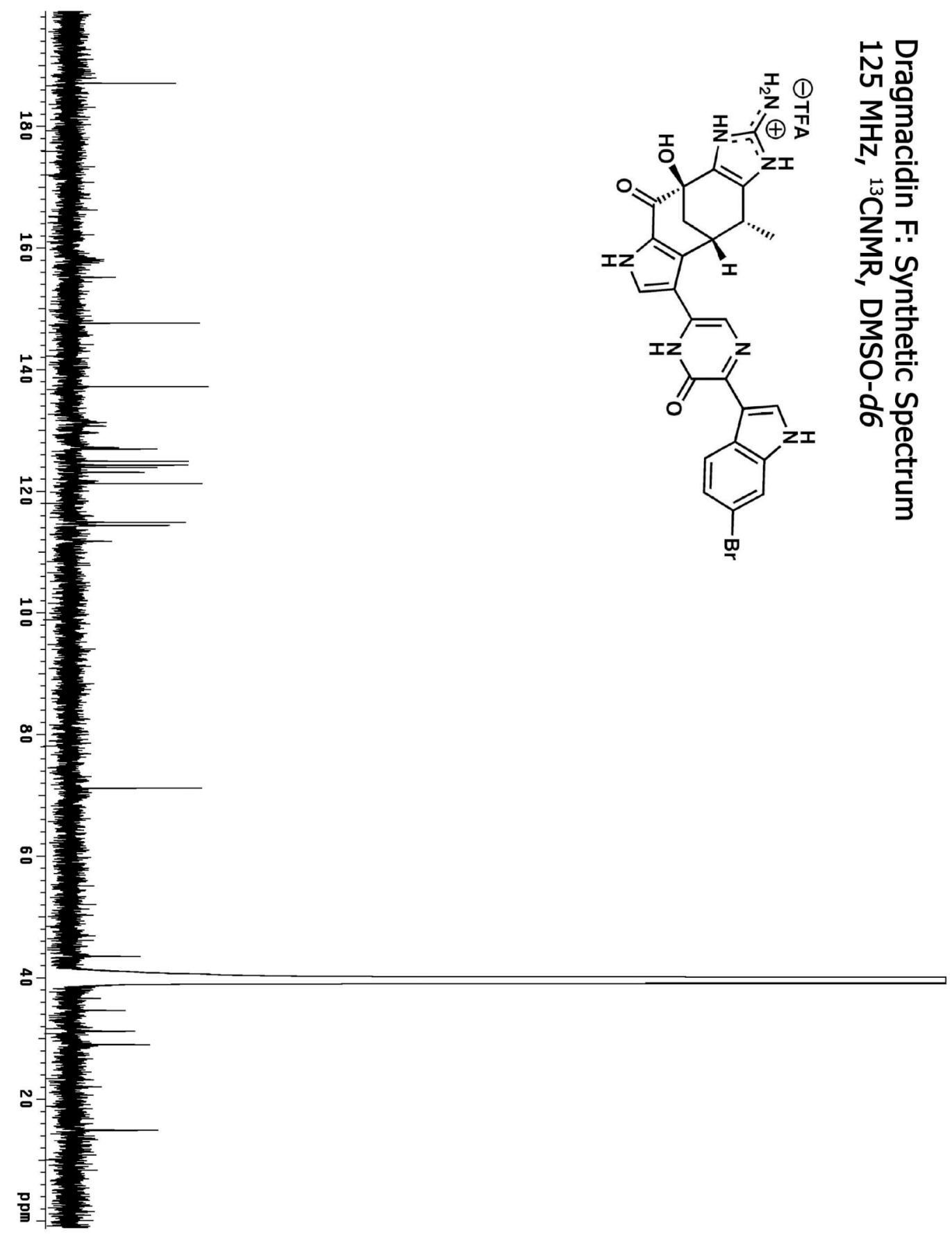




\section{Dragmacidin F Analytical HPLC Comparison:}

Analytical HPLC analysis for synthetic and natural dragmacidin F was performed on a Beckman Gold system using a Rainin $\mathrm{C}_{18}$, Microsorb MV, 5um, 300 x 4.6 mm reversed-phased column in $0.1 \%(\mathrm{w} / \mathrm{v})$ TFA with acetonitrile as eluent, flow rate of $1.0 \mathrm{~mL} / \mathrm{min}$, gradient elution of $1.25 \%$ acetonitrile/min, $10 \%$ acetonitrile $\rightarrow 60 \%$ acetonitrile over 17 minutes, UV detection $\lambda=389$ nm.

Synthetic (+)-Dragmacidin F; retention time $=13.53$ minutes:

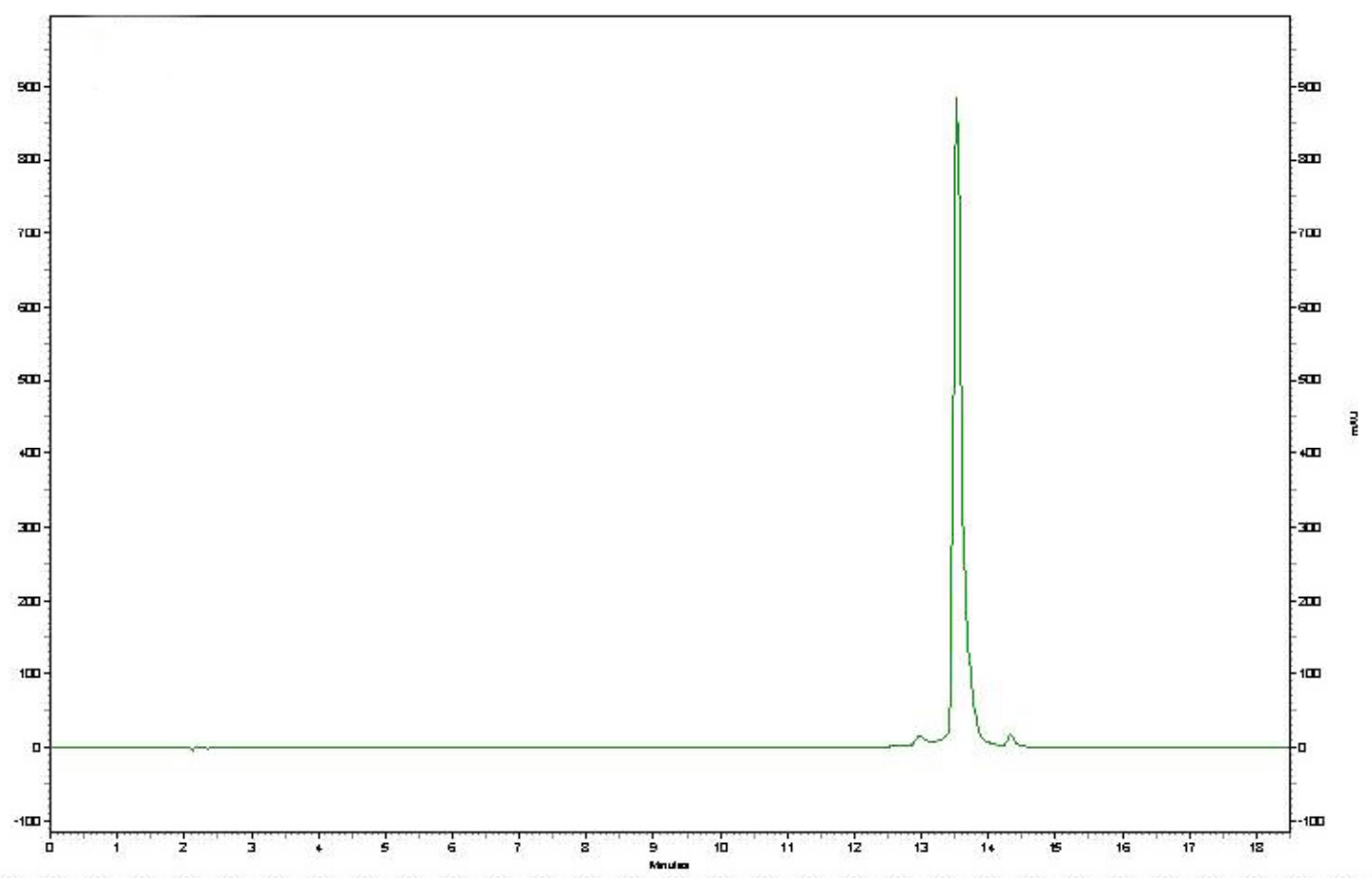


Authentic (-)-Dragmacidin F; retention time $=13.53$ minutes:

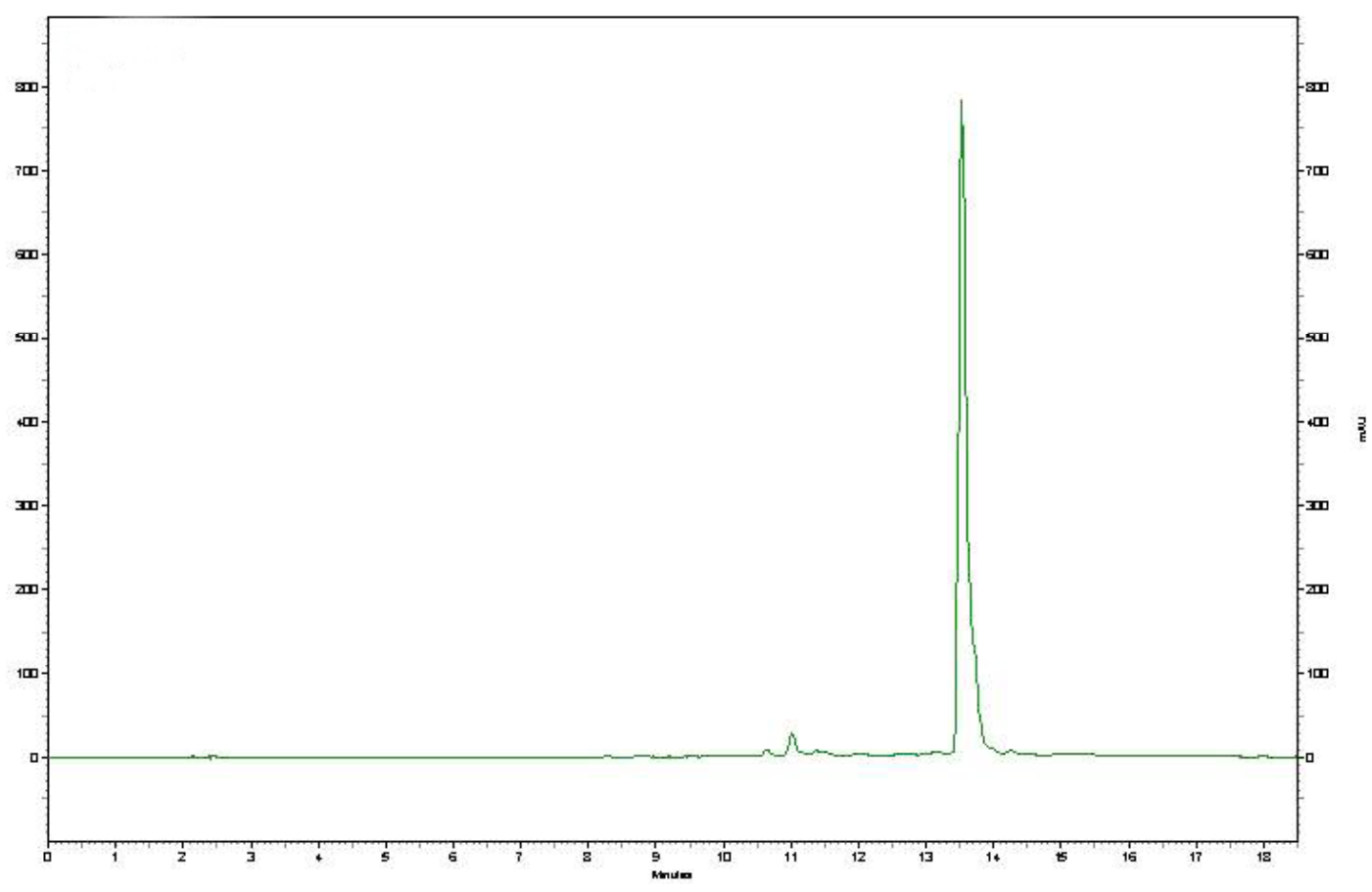

Co-injection of Synthetic (+)-Dragmacidin F \& Authentic (-)-Dragmacidin F;

retention time $=13.52$ minutes:

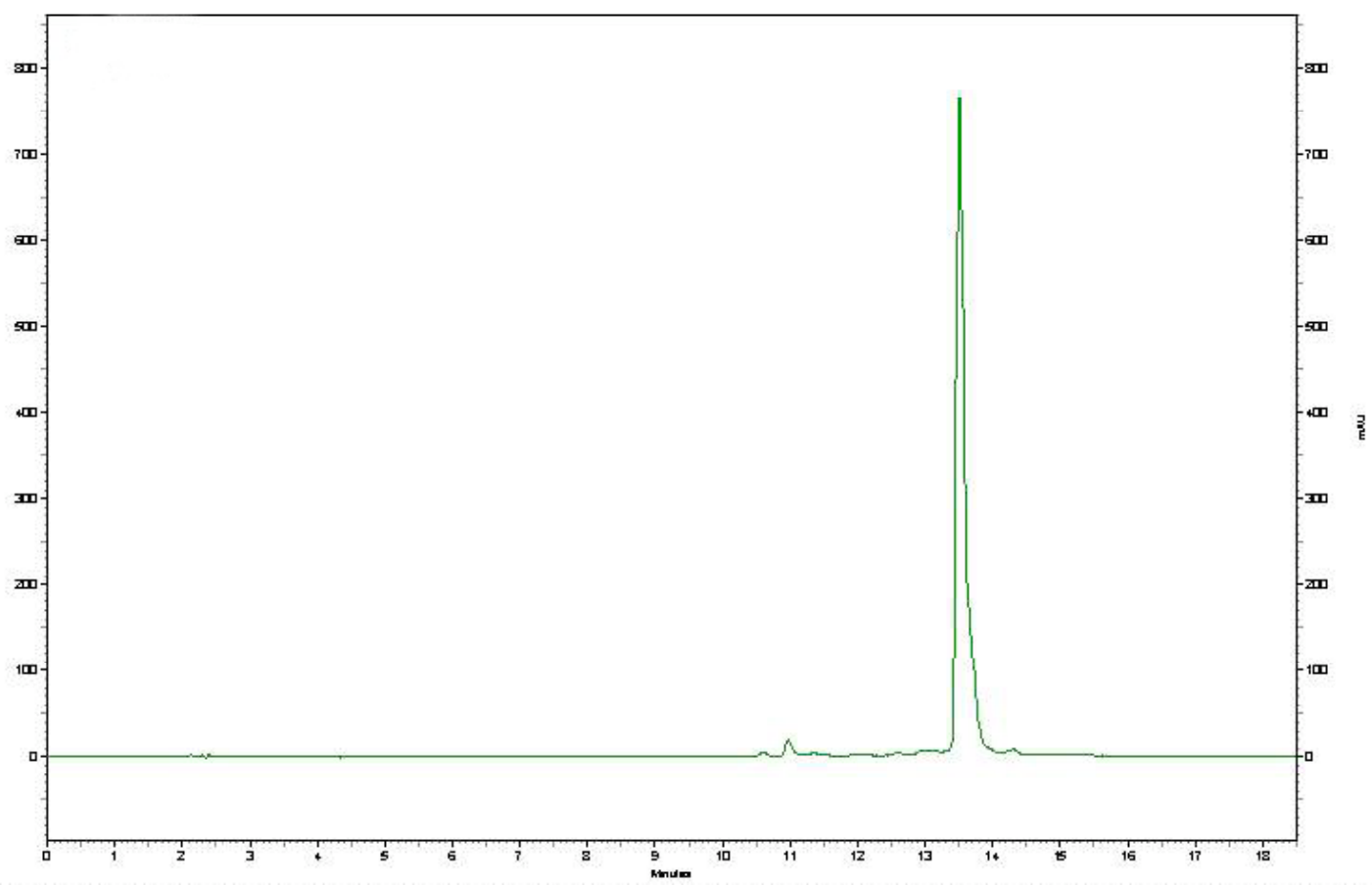

